\title{
Role of Ryanodine Receptor Subtypes in Initiation and Formation of Calcium Sparks in Arterial Smooth Muscle: Comparison with Striated Muscle
}

\author{
Kirill Essin $^{1,2}$ and Maik Gollasch ${ }^{1,2}$ \\ ${ }^{1}$ Division of Nephrology and Intensive Care Medicine, Department of Medicine, Charité Campus Virchow, 13353 Berlin, Germany \\ ${ }^{2}$ Experimental and Clinical Research Center, 13125 Berlin, Germany
}

Correspondence should be addressed to Kirill Essin, kirill.essine@charite.de and Maik Gollasch, maik.gollasch@charite.de

Received 22 June 2009; Accepted 22 September 2009

Recommended by Mohamed Boutjdir

Calcium sparks represent local, rapid, and transient calcium release events from a cluster of ryanodine receptors (RyRs) in the sarcoplasmic reticulum. In arterial smooth muscle cells (SMCs), calcium sparks activate calcium-dependent potassium channels causing decrease in the global intracellular $\left[\mathrm{Ca}^{2+}\right]$ and oppose vasoconstriction. This is in contrast to cardiac and skeletal muscle, where spatial and temporal summation of calcium sparks leads to global increases in intracellular $\left[\mathrm{Ca}^{2+}\right]$ and myocyte contraction. We summarize the present data on local RyR calcium signaling in arterial SMCs in comparison to striated muscle and musclespecific differences in coupling between L-type calcium channels and RyRs. Accordingly, arterial SMC Ca 1.2 L-type channels regulate intracellular calcium stores content, which in turn modulates calcium efflux though RyRs. Downregulation of RyR2 up to a certain degree is compensated by increased SR calcium content to normalize calcium sparks. This indirect coupling between $\mathrm{Ca}_{\mathrm{v}} 1.2$ and RyR in arterial SMCs is opposite to striated muscle, where triggering of calcium sparks is controlled by rapid and direct cross-talk between $\mathrm{Ca}_{\mathrm{v}} 1.1 / \mathrm{Ca}_{\mathrm{v}} 1.2 \mathrm{~L}$-type channels and RyRs. We discuss the role of RyR isoforms in initiation and formation of calcium sparks in SMCs and their possible molecular binding partners and regulators, which differ compared to striated muscle.

Copyright ( $) 2009$ K. Essin and M. Gollasch. This is an open access article distributed under the Creative Commons Attribution License, which permits unrestricted use, distribution, and reproduction in any medium, provided the original work is properly cited.

\section{Introduction}

$\mathrm{Ca}^{2+}$ sparks are local, rapid, and transient calcium release events from a cluster of ryanodine receptors (RyRs) in the sarcoplasmic reticulum (SR) (for recent review, see [1]). These local changes have been visualized by use of fluorescent, calcium-sensitive dyes (Fluo-3 (or 4)/AM) in all types of muscle, including arterial smooth muscle cells (SMCs). An example of $\mathrm{Ca}^{2+}$ spark recorded in a rat tibial artery SMC is shown in Figure 1. $\mathrm{Ca}^{2+}$ sparks are characterized by their spatiotemporal properties: a spatial half-width of $\sim 2 \mu \mathrm{m}$ (full-width at half maximum (FWHM)), a rise time of $\sim 20$ milliseconds, a temporal "half-duration" of $\sim 50$ milliseconds (full duration at half-maximum (FDHM)), and a peak amplitude of $\sim 1 \triangle \mathrm{F} / \mathrm{Fo}$. The skeletal sparks are briefer and smaller than those in cardiac and arterial SMCs.
$\mathrm{Ca}^{2+}$ Sparks in Smooth Muscle. In arterial SMCs, $\mathrm{Ca}^{2+}$ sparks activate the spontaneous transient outward currents (STOCs) [2, 3]. Simultaneous recording of STOCs and sparks performed in rat cerebral SMCs revealed that virtually every spark activates a STOC [4]. STOCs are mediated by big conductance calcium-activated potassium (BK) channels located in the plasma membrane. STOCs cause membrane hyperpolarization, which reduce $\mathrm{Ca}^{2+}$ influx by decreasing the open-state probability of voltage-dependent $\mathrm{Ca}_{\mathrm{v}} 1.2$ (Ltype) calcium channels, lower the global intracellular $\left[\mathrm{Ca}^{2+}\right]$, and oppose vasoconstriction [3] (Figure 2(c)).This is in contrast to cardiac and skeletal muscle, where spatial and temporal summation of calcium sparks leads to an increase in the global intracellular $\left[\mathrm{Ca}^{2+}\right]$ and myocyte contraction.

The native BK channel is composed of four poreforming Slo1 $\alpha$-subunits and four $\beta$-subunits [5]. Four $\beta$ subunit genes have been identified, each coding for proteins 
(a)

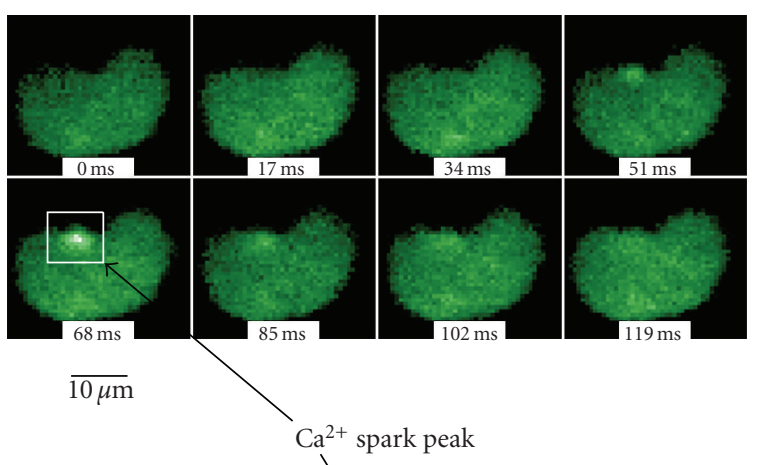

(b)

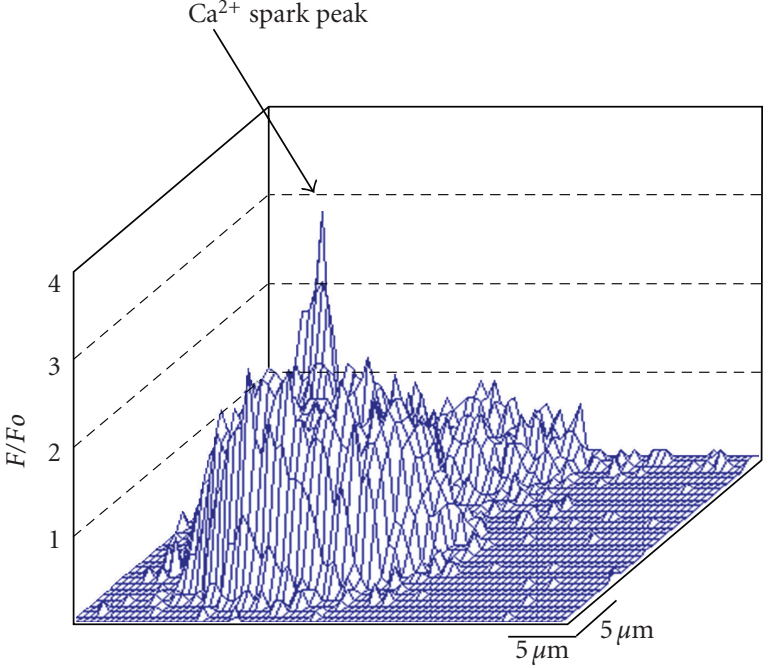

(c)

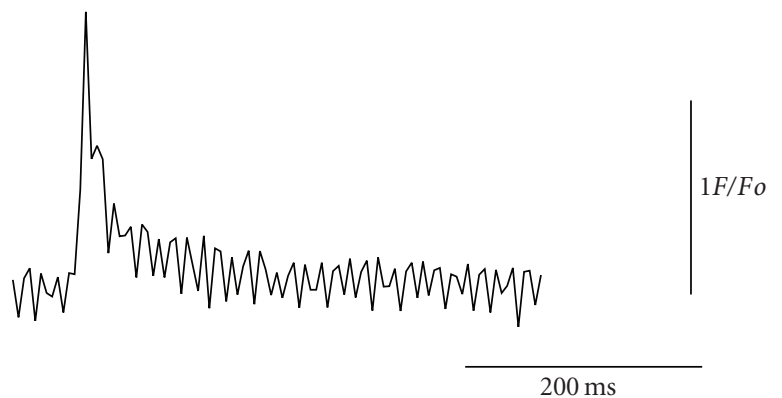

FIGURE 1: Calcium spark in a rat tibial artery smooth muscle cell. (a) Series of 8 consecutive laser scanning confocal images (17 milliseconds apart) illustrating a calcium spark. The calcium spark area is marked by a square and the peak of the calcium spark is indicated by arrows (b). The myocyte was loaded with the $\mathrm{Ca}^{2+}$ indicator dye fluo-3. Two-dimensional (2D) images were obtained using a Nipkow spinning disk confocal microscope (Perkin Elmer, UltraView LCI). (b) Three-dimensional plot of fluorescence intensity of the cell shown in (a) at 68 milliseconds. The calcium spark occurred in close proximity to the plasma membrane. (c) Time course of the calcium spark in the marked area. The amplitude is expressed as $F / F o . F$ is the fluorescence intensity in the marked area where the spark appeared. Fo is fluorescence intensity of the same cell area in the absence of calcium spark.

providing different modulatory effects on the pharmacology and activation gating of the channel. The predominant subunit in vascular smooth muscle cells is the $\beta 1$ isoform [6]. In the absence of $\beta 1$ subunits, heterologeously expressed BK channels have a dramatically reduced $\mathrm{Ca}^{2+}$ sensitivity and are open only to a significant extent at very positive membrane potentials [7]. Cerebral artery smooth muscle cells from BK $\beta 1-/-$ mice generate calcium sparks of normal amplitude and frequency, but STOC frequencies are largely reduced at physiological membrane potentials $[8,9]$. Deletion of the pore-forming BK channel alpha subunit results in a complete lack of membrane hyperpolarizing spontaneous $\mathrm{K}^{+}$outward currents, suggesting that only BK channel activity underlies STOCs in arterial smooth muscle [10]. In addition to BK channels, sparks can activate calcium-dependent chloride channels to produce transient inward currents (STICs) in nonarterial smooth muscle [11-13]. In contrast to STICs (which have been reported in only few types of smooth muscle), STOCs have been detected in virtually all smooth muscle. 


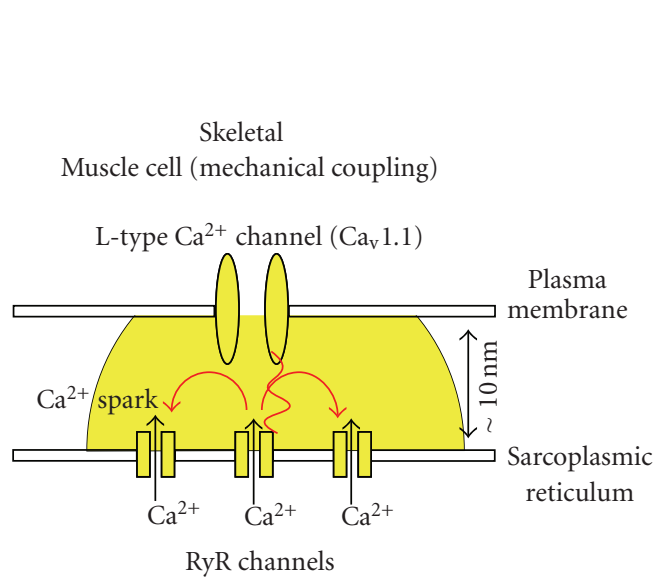

(a)

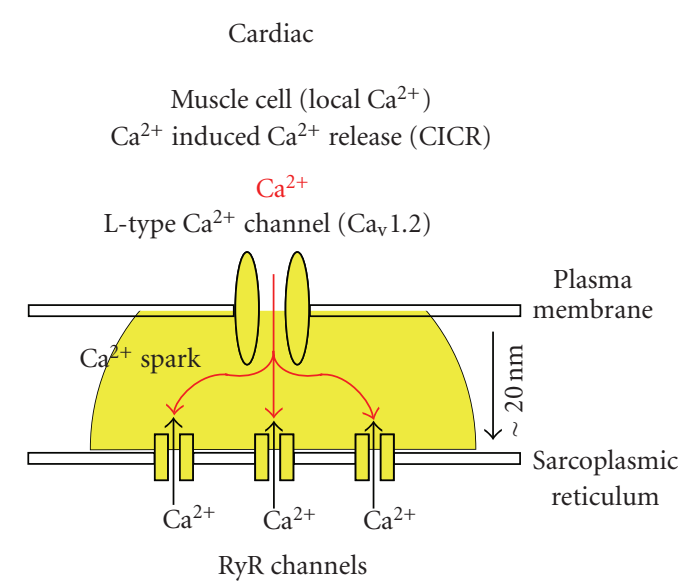

(b)

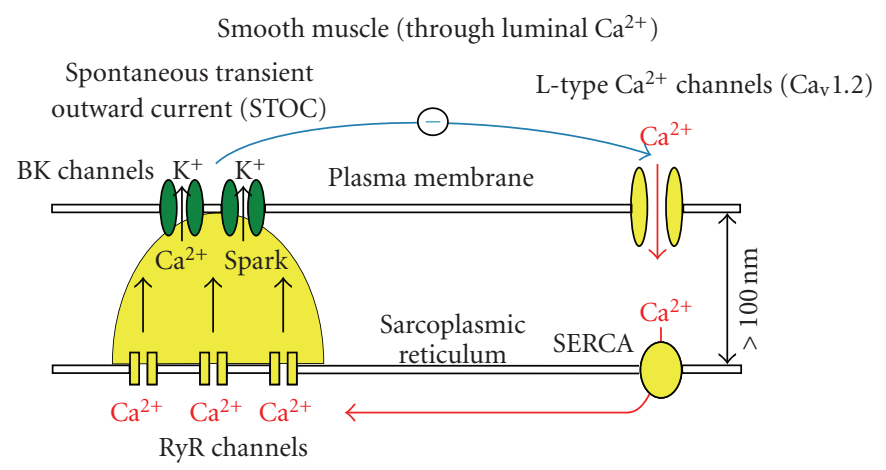

(c)

FIGURE 2: Control of calcium sparks by voltage-dependent L-type calcium channels. (a) $\mathrm{Ca}^{2+}$ entry from extracellular space is not required for calcium release in skeletal muscle. Charge movement within $\mathrm{Ca}_{\mathrm{v}} 1.1$ activates RyR1 channel via a direct physical interaction. Ca ${ }^{2+}$ efflux from SR through the opened RyR1 channel activates nearby RyR (RyR3) channels via calcium-induced calcium release (CICR). (b) In cardiomyocytes $\mathrm{Ca}_{\mathrm{v}} 1.2$ mediates influx of extracellular $\mathrm{Ca}^{2+}$ into cytosol. $\mathrm{Ca}^{2+}$ then binds to and activates RyR2 channels via CICR. (c) Triggering of calcium sparks is not controlled by rapid, direct cross-talk between $\mathrm{Ca}_{\mathrm{v}} 1.2$ channels and RyRs in smooth muscle cells in contrast to cardiac and skeletal muscle cells. Instead, $\mathrm{Ca}_{\mathrm{v}} 1.2$ channels contribute to global cytosolic [ $\mathrm{Ca}^{2+}$ ], which in turn influences luminal SR calcium and thus calcium sparks. SERCA: sarco/endoplasmic reticulum calcium ATPase, BK: big conductance calcium-activated $\mathrm{K}^{+}$ channel.

The spark-activated STOCs are important for the regulation of vascular tone, and defective spark-STOC coupling is linked to hypertension $[8,9,14]$. The spark-mediated relaxation of arteries via BK channels is a unique feature of $\mathrm{Ca}^{2+}$ sparks in arterial smooth muscle cells, making them different from cardiac and skeletal sparks. Another important difference is the unique regulation of calcium sparks by $\mathrm{Ca}_{\mathrm{v}} 1 . \mathrm{x}$ L-type channels.

$\mathrm{Ca}^{2+}$ Sparks in Skeletal Muscle. In skeletal muscle a direct mechanical interaction of the L-type channel $\left(\mathrm{Ca}_{\mathrm{v}} 1.1\right)$ and the RyR (predominantly RyR1) is thought to form the basis of excitation contraction (E-C) coupling (Figure 2(a)). In this respect, opening of $\mathrm{Ca}_{\mathrm{v}} 1.1$ channel upon membrane depolarization acts as a voltage sensor with conformational changes of the channel leading to a physical interaction with RyR1, promoting its opening, and triggering the release of $\mathrm{Ca}^{2+}$ from internal stores (Figure $2(\mathrm{a})$ and $[15,16]$ ). Thus, in skeletal myocytes, $\mathrm{Ca}^{2+}$ entry is not required for RyRmediated calcium release [17].
$\mathrm{Ca}^{2+}$ Sparks in Cardiac Muscle. In cardiac muscle, such a $\mathrm{Ca}_{\mathrm{v}} 1.1-\mathrm{RyR} 1$ mechanical coupling is absent. Instead, membrane depolarization of cardiac myocytes leads to the opening of the $\mathrm{Ca}_{\mathrm{v}} 1.2$ L-type calcium channels with $\mathrm{Ca}^{2+}$ influx through the $\mathrm{Ca}_{\mathrm{v}} 1.2$ stimulating the opening of the RyR (predominantly RyR2) and subsequent $\mathrm{Ca}^{2+}$ release from SR (Figure 2(b) and $[1,18])$. The close association between SR and plasma membrane is the morphological requisite for effective calcium induced calcium release (CICR) in cardiac cells.

Major Differences in $\mathrm{Ca}^{2+}$ Spark Triggering. Unlike CICR in cardiac muscle, RyR channel opening is not tightly linked to the gating of L-type $\mathrm{Ca}^{2+}$ channels in action potential-spiking (phasic), nonarterial smooth muscle [19, 20] and nonspiking (tonic), arterial smooth muscle [21] (Figure 2(c)). This conclusion is primarily based on the analysis of latencies between calcium sparks appearing after $\mathrm{Ca}_{\mathrm{v}} 1.2 \mathrm{~L}$-type channel opening at different membrane potentials, with the ability of $\mathrm{Ca}^{2+}$ buffers such as EGTA to 
disrupt CICR and the voltage-sensitivity of the occurrence of calcium sparks. The effective distance between $\mathrm{Ca}_{\mathrm{v}} 1.2$ and RyR in cardiomyocytes has been estimated to be $<100 \mathrm{~nm}$, while excess concentrations of EGTA $(17 \mathrm{mM})$ did not disrupt the generation of calcium sparks by $\mathrm{Ca}_{\mathrm{v}} 1.2$ channel openings. This finding is in sharp contrast to smooth muscle cells. Furthermore, the voltage sensitivity and latency to occurrence of calcium sparks in arterial smooth muscle do not correlate with the gating behavior of the $\mathrm{Ca}_{\mathrm{v}} 1.2 \mathrm{~L}$-type channel, which is also in contrast to the characteristics of calcium sparks in cardiac muscle $[22,23]$. Our experiments on conditional, inducible, smooth muscle-specific $\mathrm{Ca}_{\mathrm{v}} 1.2$ knock-out (SMAKO) mice [24] reveal that reduced calcium spark amplitudes and frequencies upon $\mathrm{Ca}_{\mathrm{v}} 1.2$ channel gene inactivation are associated with reduced $\mathrm{SR} \mathrm{Ca}^{2+}$ load [21]. The results demonstrate that triggering of calcium sparks in arterial smooth muscle is not controlled by rapid, direct cross-talk between $\mathrm{Ca}_{\mathrm{v}} 1.2$ channels and RyRs, which is in contrast to cardiac and skeletal muscle cells. Instead, the results clearly show that $\mathrm{Ca}_{\mathrm{v}} 1.2$ channels contribute to global cytosolic $\left[\mathrm{Ca}^{2+}\right]$, which in turn influences luminal SR calcium and thus $\mathrm{Ca}^{2+}$ sparks in arterial smooth muscle (Figure 2(c)). We also demonstrate that cytosolic $\left[\mathrm{Ca}^{2+}\right]$ itself contributes minimally to the acute triggering of physiologically relevant proportion of calcium sparks. Instead the most efficacious calcium spark trigger appears to be the luminal SR $\mathrm{Ca}^{2+}$, which is slowly loaded via $\mathrm{Ca}^{2+}$ influx through $\mathrm{Ca}_{\mathrm{v}} 1.2$ channels.

The SR Ca ${ }^{2+}$ content regulates excitability of $\mathrm{Ca}^{2+}$ release by stimulating RyRs by luminal calcium of $\mathrm{Ca}^{2+}$ available for release but also seems to regulate the activity of RyR receptors (for review, see $[25,26]$ ). In the following, we will discuss the role of RyR receptors subtypes in generation of calcium sparks in arterial smooth muscle. We will address the problem of changes in $\mathrm{SR} \mathrm{Ca}^{2+}$ load in experiments directed to resolve RyR-mediated, local $\mathrm{Ca}^{2+}$ signaling and will focus on sorcin, homer 1 , and calstabins.

\section{RyR Receptors Subtypes and $\mathrm{Ca}^{2+}$ Sparks}

RyR channels are tetrameric channel proteins, which are located in the SR plasma membrane and are capable to release SR Ca ${ }^{2+}$ into the cytosol [27]. Three isoforms of RyRs have been identified (RyR1, RyR2, and RyR3). RyR1 is the predominant isoform in skeletal muscle, while RyR2 is the predominant isoform in cardiac muscle. In smooth muscle, all three isoforms (RyR1, RyR2, and RyR3) are present [28, 29].

There are few drugs to target RyRs with limited isoform specificity (for recent review, see [30]). All three RyR isoforms bind the plant alkaloid ryanodine with high affinity. At low concentrations, ryanodine exhibits agonistic effects, while at higher concentrations it induces antagonistic effects on RyRs. Accordingly, calcium spark activity is stimulated by 0.1 ryanodine, but inhibited by $10 \mu \mathrm{M}$ ryanodine [31]. Caffeine can be used to stimulate RyRs. Caffeine at concentrations of $>5 \mathrm{mM}$ activates all RyR isoforms with RyR1 being less sensitive than RyR2 and RyR3 [32, 33]. The massive release of $\mathrm{Ca}^{2+}$ in response to high $\mathrm{mM}$ concentrations of caffeine reflects the amount of calcium within the SR. Low concentrations of caffeine $(<0.5 \mathrm{mM})$ increase the $\mathrm{Ca}^{2+}$ spark frequency [34]. There are several exogenous pharmacological agents that interact and modulate RyR channels [35]. For example, these include dantrolene, local anesthetics such as tetracaine and procaine, and peptide toxins. The usage of these substances in experimental studies is limited by their unspecificity. For example, dantrolene, a drug used in the treatment for malignant hyperthermia, has been reported to inhibit both RyR1 and RyR3 but not RyR2 [36]. Azumolene at $1-10 \mu \mathrm{M}$, a more water soluble analog of dantrolene, completely suppresses the frequency of calcium sparks in skeletal muscle [37]. The interpretation of the results is difficult since the drug can also block L-type channels [38]. Imperotoxins exhibit also high selectivity for RyRs [39]. Imperotoxin A, a 33-amino acid peptide isolated from the venom of the African scorpion Pandinus imperator enhances the activity of both RyR1 and RyR2 channels [40]. It is equipotent in increasing the calcium sparks frequency in skeletal and cardiac muscle $[41,42]$. Therefore, imperotoxins cannot distinguish between RyR isoforms involved in the generation of calcium sparks.

Another tool to study the role of RyR subtypes in $\mathrm{Ca}^{2+}$ sparks generation is gene targeting of RyR isoforms. RyR1 [43], RyR2 [44], and RyR3 [45] knockout mice have been generated. RyR1 knockout (dispedic) and RyR2 knockout mice die early during postnatal and embryonic development. In contrast, RyR3 knockout mice are fertile and display no gross abnormalities. Death of RyR1-/- mouse is likely caused by respiratory failure, since knockout neonates fail to breathe and do not move. Mice lacking RyR2 die at embryonic day 10 with morphological abnormalities in the heart tube. Therefore, early studies on RyR calcium signaling were carried out only on neonatal muscles from RyR2 and RyR1 knockout mice.

2.1. Skeletal Muscle: RyR1 and RyR3. The neonatal mammalian skeletal muscle contains both RyR1 and RyR3 [46, 47]. Studies on intercostal muscle cells of RyR1-/- and RyR3-/- mouse embryos reveal that both RyR1 and RyR3 isoforms seem to be responsible for calcium sparks [48]. Spatiotemporal sparks properties are not different between RyR1 and RyR3 knockout cells and disappear only in double knockout cells lacking both RyR isoforms.

RyR3 is widely expressed in murine skeletal muscles during the postnatal phase of muscle development but it is expressed only in some adult mammalian skeletal muscles $[46,49,50]$. In adult mammalian myofibres, voltage elicited calcium sparks are not detectable [51]. This can be explained by the inability to resolve individual sparks during synchronous and massive voltage-induced calcium release [52]. Mechanical stress, such as an osmotic shock, is required to evoke calcium sparks in adult mammalian skeletal muscles [53]. Osmotic shock-induced calcium sparks in RyR3 knockout flexor digitorium brevis muscles show reduced amplitudes and prolonged durations [54]. This indicates that RyR3, even when expressed at low levels, is capable to modulate calcium spark properties in adult murine skeletal muscle. RyR3 when exogenously expressed 
in skeletal muscle lacking other RyR subtypes is sufficient for calcium sparks production [55]. In contrast to adult skeletal muscle, amphibian skeletal muscle contains both RyR1 and RyR3 [56] and is able to generate calcium sparks [51, 57, 58]. A specific interplay between RyR1 and RyR3 for generation of skeletal muscle calcium sparks has been proposed. In this model, membrane depolarization activates individual $\mathrm{Ca}_{\mathrm{v}} 1.1$ channels, which in turn mechanically couple to RyR 1 channels (voltage-induced calcium release (VICR)). Calcium efflux from SR through opened RyR1 channel activates parajunctional RyR3 channels to induce calcium-induced calcium release (CICR) (see [52] and Figure 2(a)). A recent study on adult mice skeletal muscles expressing exogenous RyR3 supports this view [59]. In this study, overexpression of RyR3 produced spontaneous and voltage-operated sparks; whereas overexpression of RyR1 lacked voltage-operated sparks. However, these results could not been confirmed by Legrand et al. [60]. In this work, only spontaneous calcium release activity has been detected in GFP-RyR3 expressing regions. Further experiments are required to elucidate the question whether RyR3 is responsible for occurrence of spontaneous sparks only and/or involved in the generation of voltage-induced sparks via interplay with RyR1 in skeletal muscle cells.

2.2. Cardiac Muscle: RyR2. The predominant RyR isofom in cardiac muscle is RyR2 [56]. Accordingly, this RyR isoform is essential for cardiac excitation-contraction (E-C) coupling and cardiac calcium sparks. Cardiac myocytes derived from stem cells in vitro show calcium sparks activity which was absent after genetic ablation of RyR2 [61]. Modulation of RyR2 channel activity is achieved by endogenous regulatory proteins, including calstabin, sorcin, homer, triadin, junctin, calsequestrin. In certain heart diseases, these proteins may fail and be responsible for defective calcium spark signaling (for review, see $[1,62,63]$ ). The modulatory effects of sorcin, homer 1 and calstabin on RyR and calcium sparks are discussed in more detail below.

2.3. Smooth Muscle: RyR1, RyR2, and RyR3. In smooth muscle, all three RyR isoforms are present and may potentially participate in calcium spark generation. Several studies are undertaken to address this issue [64-70].

Using an antisense oligonucleotide strategy, it has been reported that both RyR1 and RyR2 subtypes are required for generation of calcium sparks in rat portal vein myocytes [64]. Downregulation of RyR1 and RyR2 isoforms by antisense oligonucleotides suppresses both voltage-induced sparks and global $10 \mathrm{mM}$ caffeine induced $\mathrm{Ca}^{2+}$ release, while antisense oligonucleotides against RyR3 are without effect. The requirement of RyR1 for depolarization-induced sparks has also been observed in embryonic detrusor muscle [68]. In this study, calcium sparks are measured in embryonic urinary bladder myocytes isolated from wildtype and RyR1-/mice. Depolarization-evoked sparks are present in control cells but absent in knockout cells. However, spontaneous spark activity is slightly increased in RyR $1-/-$ cells. While all three RyR isoforms are detected in myocytes, the expression of RyR2 and RyR3 is unchanged in RyR1 knockout cells. The authors conclude that both RyR2 and RyR3 are sufficient to produce spontaneous calcium sparks. Interestingly, in embryonic pulmonary vascular smooth muscle cells, the spontaneous calcium sparks frequency is reduced by genetic deletion of RyR1, suggesting the functional importance of RyR1 in spontaneous local $\mathrm{Ca}^{2+}$ release [70].

The contribution of RyR2 to smooth muscle calcium spark generation is indirectly demonstrated using FKBP12.6 knockout mice $[67,71]$. Based on the observation that FKBP12.6 (or calstabin2) stabilizes RyR2 channel in closed state, deficiency of FKBP12.6 shows an increase in calcium spark and STOC frequency, amplitude, and duration in urinary bladder myocytes, indicating a role of RyR2 in this action potential-spiking smooth muscle. There is more direct evidence for the involvement of RyR2 in excitationcontraction coupling in adult urinary bladder using heterozygote RyR+/- mice [69]. The RyR2 mRNA expression level is approximately twice higher than those of RyR1 and RyR3 in control $+/+$ cells indicating predominant expression of RyR2. In +/- cells, the expression of RyR2 mRNA is significantly reduced, while RyR1 and RyR3 mRNA expression are not altered. This reduction of RyR2 expression is associated with a decrease of STOC frequency and amplitude. The frequency of depolarization evoked $\mathrm{Ca}^{2+}$ "hot spots," that represent local calcium transients consisted of several merged $\mathrm{Ca}^{2+}$ sparks [72], is also decreased in $+/-$ cells. The data suggest involvement of RyR2 in spiking smooth muscle calcium spark production. Genetic ablation of RyR3 does not altered $\mathrm{Ca}^{2+}$ spark and STOC characteristics in mouse urinary bladder myocytes [67]. These data indicate a role of RyR2 in calcium spark signaling in action potential-spiking, nonarterial smooth muscle. Nevertheless, the role of RyR2 in calcium spark formation in nonspiking (tonic) arterial smooth muscle cells is unknown.

The first study that has been addressed the role of RyR isoforms in calcium spark signaling in nonspiking, arterial smooth muscle has been performed by Lohn et al. using RyR3-/- mice [65]. In this study, calcium sparks, STOCs, and myogenic tone of cerebral arteries have been analyzed. The study shows that cells lacking RyR3 produced more calcium sparks and STOCs leading to reduced arterial myogenic tone than wildtype cells. The specific role of RyR3 in calcium spark signaling in nonspiking smooth muscle compared to spiking smooth muscle may be caused by different expression levels and/or splicing variants of RyR3. Nevertheless, the data show that there is a specific intermolecular interaction between RyR3 and RyR1/2 in arterial smooth muscle. A possible explanation is proposed in this paper based on the report that RyR3 are less sensitive to $\mathrm{Ca}^{2+}$ dependent inactivation than RyR1 and RyR2 [73]. Accordingly, prolonged $\mathrm{Ca}^{2+}$ release through RyR3 will inactivate RyR1 and RyR2 channel activity. In line with this suggestion, deficiency of RyR3 eliminates inactivation of RyR1 and RyR3 and stimulation calcium sparks/STOCs activity in arterial smooth muscle. However, other studies do not report a low sensitivity of RyR3 to $\mathrm{Ca}^{2+}$ inactivation [74]. Further studies are required to clarify the precise molecular mechanism of RyR-dependent calcium spark signaling and the role of RyR3 in this process. 
As discussed above, studies on the role of RyR2 in generation of calcium sparks in arterial smooth muscle are hampered by the fact that RyR2-I- mice die early during embryonic development and RyR-dependent elementary calcium signaling develops relatively late during postnatal development in arterial smooth muscle [75]. In an attempt to fill the gap of knowledge, we performed experiments on rats treated with antisense oligonucleotides (asODNs) to downregulate RyR2. The approach is based on a recent work of Reading and Brayden and allows partial downregulation of channels in situ [76]. In situ suppression of RyR2 expression in cerebral artery myocytes was achieved by infusion of $1 \mathrm{mmol} / \mathrm{L}$ asODNs into the cerebral spinal fluid of 300 to $400-\mathrm{g}$ Sprague-Dawley rats at a rate of $1 \mu \mathrm{L}$ per hour for 7 days via Alzet osmotic pumps that discharged into the lateral cerebral ventricle. The antisense (AS) and control scrambled (SC) ODNs sequences for RyR2 were taken from Coussin et al. [64] and synthesized by BioTeZ, Berlin, Germany. In some experiments, fluorescein-labeled AS was used to control the delivery of AS (Figure 3(a), left). The efficiency of downregulation of RyR2 was controlled by quantitative TaqMan RT-PCR (Figure 3(a), right). Gene expression was measured using primers obtained from Applied Biosystems, Darmstadt, Germany and normalized by $18 \mathrm{~S}$ ribosomal RNA expression (for method and primer sequences, see [77]). After 7 days treatment with ODNs, rats were killed and freshly isolated cerebral smooth muscle cells were loaded with calcium-sensitive Fluo-4 AM fluorescent dye (for method, see [75]). We found that $10 \mathrm{mM}$ caffeine induced calcium release was significantly increased in AS-treated cells in comparison to SC-treated control cells (Figure 3(b), left). This indicates that SR $\mathrm{Ca}^{2+}$ load is upregulated in response to partial suppression of RyR2 by the asODNs. Although calcium spark frequency had a tendency to increase in AS-treated cells (Figure 3(b), right), the effect was not significant. Thus, a partial reduction of RyR2 expression seems to increase SR $\mathrm{Ca}^{2+}$ load to normalize $\mathrm{Ca}^{2+}$ sparks in rat cerebral artery smooth muscle cells. Accumulation of $\mathrm{Ca}^{2+}$ inside the SR may have resulted from an inhibition of $\mathrm{Ca}^{2+}$ efflux through reduced number of available RyR2 channels. The SR $\mathrm{Ca}^{2+}$ overload, in turn, may stimulate $\mathrm{Ca}^{2+}$ spark activity through a process known as store-overload induced $\mathrm{Ca}^{2+}$ release (SOICR) [78].

\section{Intracellular Proteins, Stores Regulation (SR), and $\mathrm{Ca}^{2+}$ Sparks}

The SR Ca ${ }^{2+}$ load $\left(\left[\mathrm{Ca}^{2+}\right]_{\mathrm{SR}}\right)$ does not only determine the amount of $\mathrm{Ca}^{2+}$ available for release from SR but seems also to regulate the activity of RyR receptors. In agreement, luminal $\mathrm{Ca}^{2+}$ has been shown to enhance RyR2 channel activity (for recent review, see [79]). It has been suggested that luminal $\mathrm{Ca}^{2+}$ regulates cardiac $\mathrm{Ca}^{2+}$ release channel activity by passing through the open channel and binding to the channel's cytosolic $\mathrm{Ca}^{2+}$ activation sites [80]. An alternative scenario assumes the existence of $\mathrm{Ca}^{2+}$ sensitive site(s) at the luminal face of the RyR2 channel [81]. RyR1 channels have been found to be less sensitive to the $\mathrm{Ca}^{2+}$ overload and luminal $\mathrm{Ca}^{2+}$ than RyR2 channels, which has been proposed as a possible explanation for the lack of spontaneous $\mathrm{Ca}^{2+}$ sparks in adult mammalian skeletal muscles [78]. $\mathrm{Ca}^{2+}$ overload and associated increase in $\mathrm{Ca}^{2+}$ sparks frequency are detected in rat cardiomyocytes upon treatment with tetracine $(0.75 \mathrm{mM})$, a membrane-permeant reversible blocker of RyR2 and RyR1 channels [82]. However, recent studies on smooth muscle cells explore lower concentrations of tetracaine $(\leq 50 \mu \mathrm{M})$ and reveal that the inhibitory effects of tetracaine on $\mathrm{Ca}^{2+}$ sparks are rather independent on SR $\mathrm{Ca}^{2+}$ load $[83,84]$. Nevertheless, a good correlation between $\mathrm{SR} \mathrm{Ca}^{2+}$ load and $\mathrm{Ca}^{2+}$ sparks/STOCs activity is observed in nonspiking, nonarterial smooth muscle $[83,85]$. In addition, genetic ablation of phospholamban, an endogenous inhibitor of the SR Ca ${ }^{2+}$-ATPase, leads to a chronic elevation in SR $\mathrm{Ca}^{2+}$ load and calcium spark frequency in arterial smooth muscle cells compared to wild type cells [86]. There are several endogenous proteins known to modulate $\mathrm{Ca}^{2+}$ sparks activity. The role of calsequestrin, junction, and triadin is excellently reviewed in [62]. In the following, we will focus on the natural modulators of RyR channels known to date, such as sorcin, homer1, and calstabins, and discuss their functions to regulate calcium sparks and $\mathrm{SR} \mathrm{Ca}^{2+}$ load (Figure 4).

3.1. Sorcin. Sorcin (soluble resistance-related calcium binding protein) is a $21.6-\mathrm{KDa}$ protein that regulates intracellular $\mathrm{Ca}^{2+}$ homeostatsis and expressed in a variety of mammalian tissues including the heart [87], endothelial and smooth muscle cells of the aorta and cerebral arteries [88]. Expression of sorcin in rat aorta is $\sim 2$-fold higher than in heart and small cerebral artery, indicating a prominent role in conduit arteries [88]. Sorcin reduces the activity of RyR2 in cardiac SR vesicles incorporated into planar lipid bilayers [87] and slows inactivation of $\mathrm{Ca}_{\mathrm{v}} 1.2$ in isolated rabbit ventricular myocytes [89]. Sorcin also induces activation of sodiumcalcium exchanger, sarco/endoplasmic reticulum calcium ATPase (SERCA) - mediated $\mathrm{Ca}^{2+}$ uptake, and increases in $\mathrm{SR} \mathrm{Ca}^{2+}$ load $[90,91]$.

Sorcin and $\mathrm{Ca}^{2+}$ Sparks. Sorcin inhibits calcium spark frequency and alters their characteristics in permeabilized mouse ventricular myocytes [87] and permeabilized rat cerebral artery smooth muscle cells [88]. The ability of sorcin to reduce calcium spark frequency is associated with its inhibitory effects on RyR. The inhibitory process is $\mathrm{Ca}^{2+}$ dependent. Sorcin is largely soluble at low $\left[\mathrm{Ca}^{2+}\right]$ $(<1 \mu \mathrm{m})$ and supposedly inactive, but at high $\left[\mathrm{Ca}^{2+}\right]$ it undergoes conformational changes that expose hydrophobic residues and trigger translocation of sorcin from cytosol to membrane-bound protein targets. In the heart this process requires a much higher increase in intracellular $\left[\mathrm{Ca}^{2+}\right](\mathrm{EC} 50$ $\approx 200 \mu \mathrm{M},[87])$ in comparison to SMCs $(\mathrm{EC} 50=1.5 \mu \mathrm{M}$, [88]). Rueda et al. assume that this difference reflects the difference in coupling between the $\mathrm{Ca}_{\mathrm{v}} 1.2$ channels and RyR2 in cardiac versus smooth muscle cells. According to their assumption, sorcin translocation in cardiac cells is initiated only in the dyadic space (the gap between T-tubules and SR membranes), where the tight interaction between 

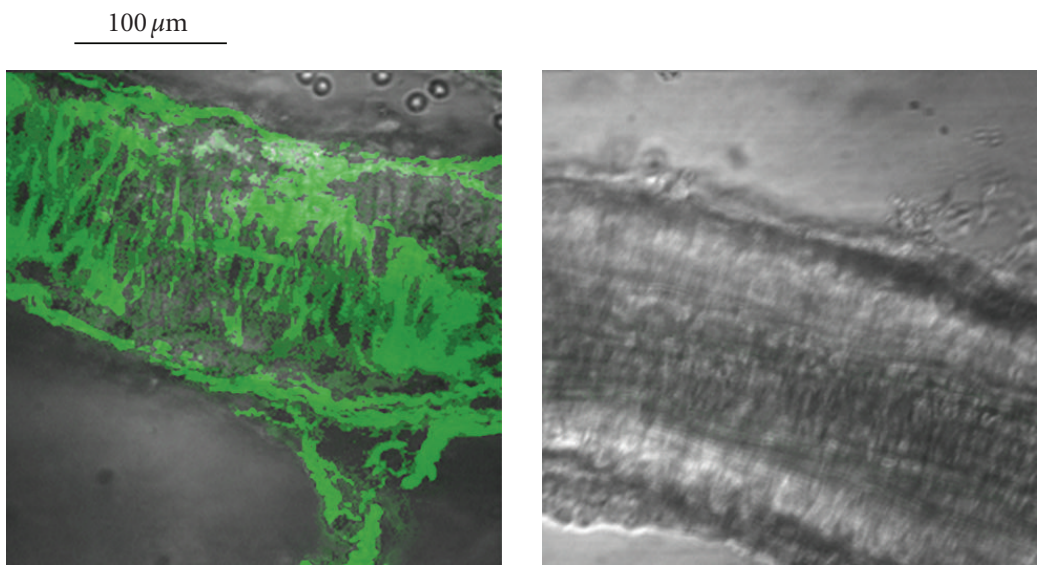

(a)

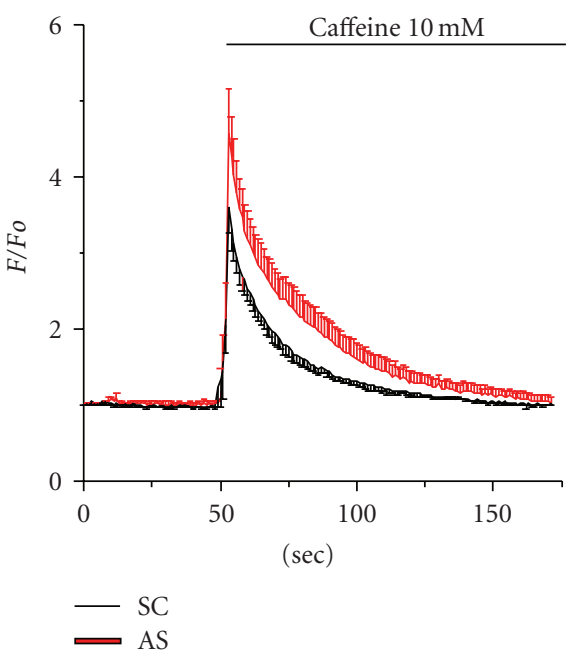

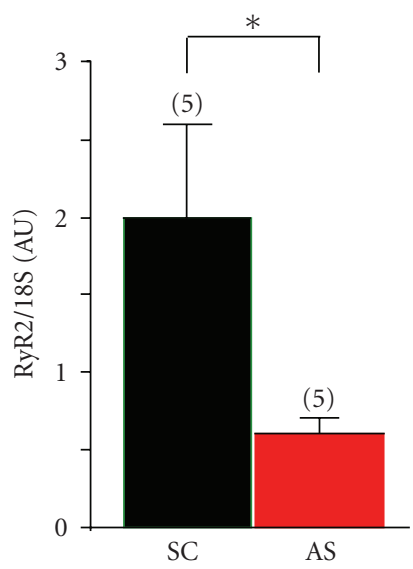

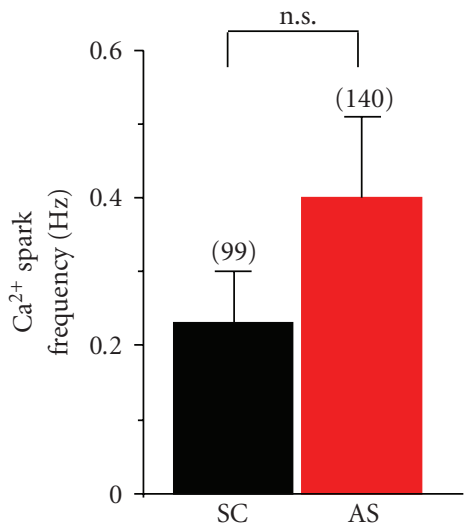

(b)

FIGURE 3: In vivo suppression of RyR2 expression by antisense oligonucleotides (AS ODNs) in rat cerebral artery smooth muscle cells leads to increase of $S R \mathrm{Ca}^{2+}$ content without effects on spontaneous calcium sparks. (a) Left side: Images of rat cerebral arteries isolated 7 days after continuous i.c.v. injection of the fluorescence-labled AS ODNs (left) and nonlabeled AS ODNs (right) via Alzet osmotic pumps. Right side: RyR2 mRNA expression normalized to $18 \mathrm{~S}$ ribosomal mRNA expression in arteries isolated from rats treated by AS ODNs (red) and scrambled (SC) ODNs (black) ( $n=5$ rats in each group). (b) Left side: Averaged time course of changes in response to external $10 \mathrm{mM}$ caffeine in fluorescence intensity in Fluo-4 loaded cerebral artery smooth muscle cells (SMCs) isolated from rats treated with AS ODNs (red) and SC ODNs (black). The corresponding mean peak amplitudes are presented in the middle plot. Right side: The frequency of calcium sparks was not different between AS and SC ODNs treated cells. Calcium sparks were recorded in line-scan mode. The number of cells tested is indicated above each bar. Data are mean \pm S.E.M. AU: arbitrary unit.

$\mathrm{Ca}_{\mathrm{v}} 1.2$ and RyR2 generates $\mathrm{Ca}^{2+} \leftarrow$ gradients that have been estimated to reach several hundred micromolars. The absence of such a tight coupling between $\mathrm{Ca}_{\mathrm{v}} 1.2$ and RyRs in smooth muscle $[19,21]$ and therefore the presence of smaller $\mathrm{Ca}^{2+} \leftarrow$ gradients would require a higher calcium sensitivity of sorcin-RyR2 interaction to be functionally activated in these cells. The reasons for the remarkable differences in calcium sensitivity are unclear. One possibility [88] is the presence of $\beta 1$-adrenergic inactivation of sorcin via protein kinase A in cardiac cells [92], which is not noted in smooth muscle cells.
Sorcin Mutation. A sorcin missense mutation (F112L) has been associated with hypertrophic cardiomyopathy and hypertension in two unrelated families [93]. The F112L mutation results in $\sim 6$-fold decrease in the affinity for $\mathrm{Ca}^{2+}$ and lack of ability to modulate RyR2 activity [94]. As a result, F112L-sorcin does not decrease the frequency, amplitude, duration, and spatial spread of calcium sparks in saponin-permeabilized vascular myocytes [94]. Moreover, overexpression of F112L-sorcin in transgenic mice increases calcium spark frequency, duration, and width in cardiomyocytes [91]. The reason for the increased SR $\mathrm{Ca}^{2+}$ content 


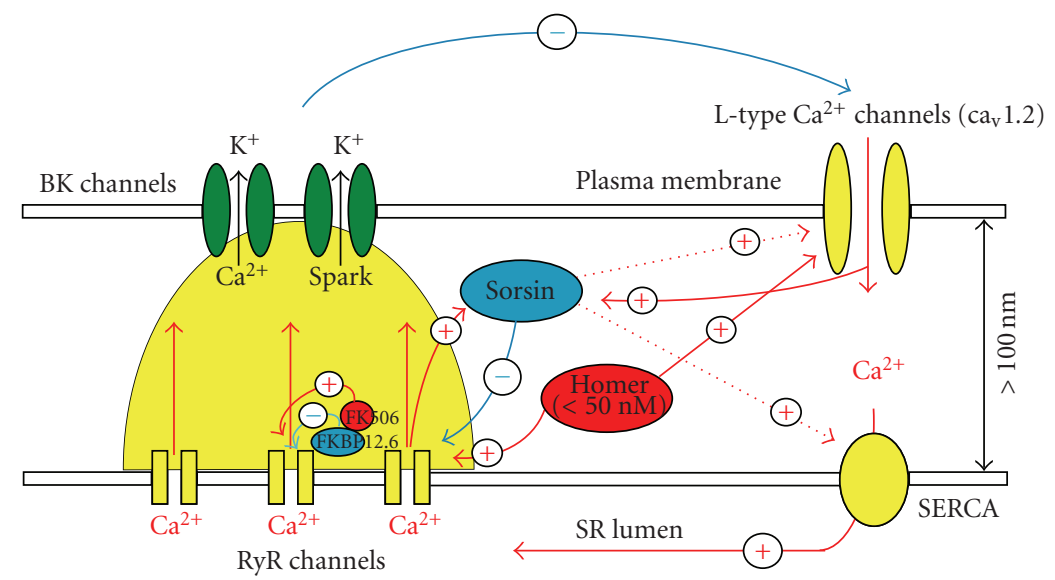

FIGURE 4: Putative role of sorcin, homerl, and calstabins in calcium spark regulation in smooth muscle. Sorcin (soluble resistance-related $\mathrm{Ca}^{2+}$ binding protein) is a negative regulator of calcium sparks in SMCs. It is activated by increases in cytosolic [Ca $\left.{ }^{2+}\right](\mathrm{EC} 50=1.5 \mu \mathrm{M})$. Stimulatory effects on $\mathrm{Ca}_{\mathrm{v}} 1.2$ channels and SERCA have also been reported. Calstabin2 (FKBP12.6) associates with RyR2 and stabilizes RyR2 channels in their closed state. FK506, an immunodepressant drug, binds to calstabin2 and can cause dissociation of calstabin2-RyR2 complex and therefore stimulation of calcium sparks in some smooth muscle tissues. Scaffold protein Homer1 (Ves1) has been shown to stimulate both RyR2 (at doses $<50 \mathrm{nM}$ ) and $\mathrm{Ca}_{\mathrm{v}} 1.2$ channels in nonarterial smooth muscle. Based on these findings, Homer1 can be expected to be a positive regulator of local calcium release calcium in this type of smooth muscle, which, however, has not been demonstrated so far. With respect to arterial smooth muscle, it is likely that calstabin2 and Homer1 play no role or only a minor role in calcium spark generation. This speculation is based on our findings that cytosolic $\left[\mathrm{Ca}^{2+}\right]$ itself contributes minimally to the acute triggering of physiologically relevant proportion of calcium sparks. Instead the most efficacious calcium spark trigger appears to be the luminal SR Ca ${ }^{2+}$, which is slowly loaded via $\mathrm{Ca}^{2+}$ influx through $\mathrm{Ca}_{\mathrm{v}} 1.2$ channels. Arrows indicate positive $(\mathrm{red},+)$ and negative (blue, - ) regulation of corresponding targets.

is likely delayed inactivation of $\mathrm{Ca}_{\mathrm{v}} 1.2 \mathrm{Ca}^{2+}$ channels, which has been revealed by overexpression of sorcin. Another reason could be sorcin mediated activation of SERCA [90]. However, the vascular phenotype and calcium spark properties had not been studied.

Therefore, sorcin appears to play an opposite role in calcium spark regulation. First, it inhibits calcium sparks by decreasing the activity of RyR2s. Second, it stimulates calcium sparks by increasing SR $\mathrm{Ca}^{2+}$ content. Under normal conditions, the inhibitory effect seems to dominate. In disease, F112L-mutated sorcin lacks the ability to modulate RyR2 activity, which may unmask the stimulatory effect of sorcin on calcium sparks frequency [91]. There is no data on the role or function of sorcin in arterial smooth muscle.

3.2. Homer1. Homer1 (known also as Ves1) belongs to the Homer scaffolding protein family and modulates not only the targeting and localization, but also the activity of many proteins participating in calcium signaling, including RyR1, RyR2, and $\mathrm{Ca}_{\mathrm{v}} 1.2$ (for recent review, see [95]). In mammals, the Homer proteins are found in brain, heart, skeletal, and smooth muscles [96]. There are four Homerl isoforms: short Homerla isoform and long Homer1b/c/d isoforms. Both long and short isoforms interact with RyR1 and RyR2 through conserved EVH1 domain binding to proline-rich binding sites on the RyR protein. The effect of Homer1 isoforms on the single channel activity of RyR incorporated into lipid bilayer is biphasic, being stimulatory at low doses of Homer $1(<50 \mathrm{nM})$ and inhibitory at high doses of Homer 1 $(>200 \mathrm{nM})[97,98]$.
Long and Short Homer. Long (1c) and short (1a) Homer1 isoforms dosedependently $(0-50 \mathrm{nM})$ increase the frequency of calcium sparks in permeabilized skeletal muscle without significant alteration of their spatiotemporal properties [99]. No changes in calcium sparks are detected upon application of Homer1c with mutation in the EVH1 binding domain, what suggest that enhanced calcium spark activity is mediated by an interaction of the EVH1 domain of Homer with the Homer ligand domain of RyRs. Homer1c isoform is more effective in increasing the skeletal muscle calcium spark frequency in comparison with Homerla, a finding that correlates with the higher efficiency of Homer1c in modulation RyR1 [97]. Homer1a, in contrast to long Homer isoforms, lacks a C-terminal coiled coil (CC) domain that serves to form a multimeric Homer complex and link the proteins that bind EVH1 domain. Homerla stimulates spark frequency in skeletal muscle, which is most likely induced by agonistic effects of Homer on RyR1, but not by the capacity of Homer to link $\mathrm{Ca}_{\mathrm{v}} 1.1$ to RyR1 [99].

Effects on $\mathrm{Ca}^{2+}$ Sparks. The effects of Homer1 on calcium sparks in cardiac and smooth muscle have not been investigated so far. However, there is evidence that Homer1 can stimulate $\mathrm{Ca}_{\mathrm{v}} 1.2$ currents in destructor smooth muscle [100]. Deletion of Homer1 in mice resulted in a $\sim 40 \%$ reduction of $\mathrm{Ca}_{\mathrm{v}} 1.2$ current. Infusion of either short or long Homer1 isoforms activates $\mathrm{Ca}_{\mathrm{v}} 1.2$ and restored the current amplitude in Homer1-/- cells. The intriguing finding is that despite the significant reduction of $\mathrm{Ca}_{\mathrm{v}} 1.2$ current, the efficiency of E-C coupling is increased in Homer1-/- 
cells. To explain this finding, the authors propose existence of a Homer-mediated link between $\mathrm{Ca}_{\mathrm{v}} 1.2$ and RyRs in this type of smooth muscle. According to this explanation, long isoforms of Homer1 solidify the interaction between $\mathrm{Ca}_{\mathrm{v}} 1.2$ and RyRs and reduce the activity of the channels. Therefore, knockout of Homer1 facilitates the interaction between the $\mathrm{Ca}_{\mathrm{v}} 1.2$ and RyRs (most likely RyR2) and results in an increased E-C coupling. In the elegant experiments performed on HEK cells simultaneously transfected with $\mathrm{Ca}_{\mathrm{v}} 1.2$, RyR2 and Homer1, the existence of a Homer1mediated link between $\mathrm{Ca}_{\mathrm{v}} 1.2$ and RyR2 is confirmed [100]. Experiments on native cardiac and smooth muscle cells are required to confirm the existence of this pathway in vivo. Calcium spark measurements in Homer1-/- cells would be essential to clarify the physiological importance of this pathway for local calcium signaling.

3.3. Calstabins (FKBPs). Calstabins (FKBPs, or FK506 binding proteins) represent a family of proteins that exhibit prolyl isomerase activity and are widely expressed in a variety of tissues. Two members of the FKBP family, FKBP12 (calstabin1) and FKBP12.6 (calstabin2), can associate and stabilize RyR channels in the closed states (for recent review, see [101]). The immunosuppressive agents, FK506 (tacrolimus) and rapamycin (sirolimus), are drugs known to cause dissociation of FKBP12 from RyR, thus stimulating RyR channel activity. FK506 disrupts the FKBP12-RyR complex and forms the FK506-FKBP12 complex, which inhibits the $\mathrm{Ca}^{2+} /$ calmodulin-dependent phosphatase calcineurin [102]. Rapamycin, a structural analog of FK506, can also form a complex with FKBP12. The rapamycin-FK506 complex is found to inhibit a protein kinase named mammalian target of rapamycin (mTOR) [103]. Under physiological conditions, FKBP12 binds selectively to RyR1, and FKBP12.6 associates predominantly with the RyR2 isoforms [104]. In this respect, excitation-contraction coupling in general and calcium sparks in particular can be modulated by calstabins.

Calstabins in Skeletal Muscle. In skeletal muscle, E-C coupling is gained by deficiency FKBP12, as shown in skeletalmuscle specific FKBP12 knockout mice (SFK12KO mice) [105]. Calcium sparks properties in SFK12KO cells have not been studied so far. Nevertheless, a modulatory effect of FKBP12 on skeletal muscle calcium sparks has been implicated by experiments in rats with chronic hyperadrenergic heart failure, where protein kinase A (PKA) hyperphosphorylation of RyR is known to decrease calstabin binding to RyR [106]. Additional support comes from a recent study using K-201 (known also as JTV519) [107], a 1,4-benzothiazerpine derivative, a drug that has been suggested to prevent dissociation of calstabin-RyR complex. Considering the multiplicity of targets of PKA and K-201, including their direct action on $\mathrm{Ca}_{\mathrm{v}} 1 . \mathrm{x}$ and SERCA activity, the reported effects of PKA and K-201 on calcium sparks cannot be exclusively explained by changes in calstabinRyR complex stability. Future work, for example, utilizing the SFK12KO mice model, is required to determine the degree by which the decreased gain of skeletal muscle E-C coupling following disruption of the FKBP12-RyR1 interaction involves alterations in the properties of calcium sparks.

Calstabins in Cardiac Muscle. In cardiomyocytes, deficiency of FKBP12.6 leads to an increase in calcium spark amplitude and duration, which is consistent with an increase in RyR channel openings [108]. Similarly, inhibition of FKBP by the FK506 or rapamycin increases calcium spark duration by 6-7 fold in rat ventricular myocytes. However, this finding is in contrast to data on FKBP12.6 knockout mice, which show slightly decreased calcium spark amplitudes [109]. Divergent effects of FK506 on $\mathrm{Ca}^{2+}$ transient amplitude can be related to species differences [110]. An increase in cardiac spark frequency accompanied by increase of $\mathrm{SR} \mathrm{Ca}^{2+}$ content upon treatment by FK506 has also been reported [111]. Overexpression of FKBP12.6 in cardiomyocytes decreases the calcium spark frequency $(>50 \%)$ with little effects on spatial-temporal characteristics [112-114]. The controversy raises since rat and rabbit cardiomyocytes overexpressing FKBP12.6 after adenoviral-mediated gene transfer show an increased SR calcium load $[112,113]$, which is not detectable in mouse cardiomyocytes after conditional cardiac-specific overexpression of FKBP12.6 [114]. Therefore, despite of numerous studies of the FKBP12.6 effects on cardiac calcium sparks, the precise role of FKBP12.6 in local cardiac calcium signaling, including its contribution to the calcium SR load, remains to be resolved. To make the picture even more complicated, recent work on FKBP12.6-/- mice demonstrates no effect of the calstabin2 loss on the RyR2 activation and spontaneous $\mathrm{Ca}^{2+}$ release [115].

Calstabins in Smooth Muscle. Similar to the situation with cardiac cells, in mouse urinary bladder smooth muscle cells, knockout of FKBP12.6 evokes an increase in calcium spark and STOC frequencies, amplitudes, and durations [67]. Pharmacological removal of calstabins from RyR by FK506 induces augmentation of calcium spark and STIC frequencies, amplitudes, and durations in tracheal smooth muscle cells [71] and increases STOCs in guinea-pigs urinary bladder smooth muscle cells [116]. These effects correlate with the ability of FK506 to increase the open probability of reconstituted smooth muscle RyR channels [117]. The effects of FKBP12.6 on caclium sparks in arterial smooth muscle have not been studied. It is known that in arterial smooth muscle calcium sparks indirectly cause vasodilation through activation of BK channels [3]. Based on an increased spark activity detected in FKBP12.6 knockout smooth muscle cells, a vasodilatory phenotype would be expected in FKBP12.6-/- mice. Instead, calstabin2 knockout mice are hypertensive [108], which could be related to endothelial dysfunction and abolishment of endothelium-dependent dilations in the absence of calstabin2 [118]. Nevertheless, calcium sparks and STOCs have not been analyzed in arterial smooth muscle of these mice, making the interpretation of the results difficult.

\section{4. $\mathrm{Ca}^{2+}$ Sparks and Functional Disorders}

Alterations in $\mathrm{Ca}^{2+}$ spark properties are detected in many muscle disorders-from skeletal muscle dystrophy and 
cardiac hypertrophy to arterial hypertension. In skeletal muscle, $\mathrm{Ca}^{2+}$ sparks are silent under resting conditions in young muscle but can be repeatedly and reversibly activated upon deformation of membrane structures. The ability to activate $\mathrm{Ca}^{2+}$ sparks repeatedly is reduced in aged skeletal muscle [119]. In dystrophic muscle, deformation-induced $\mathrm{Ca}^{2+}$ sparks are essentially irreversible [53]. Deformations applied to the skeletal muscle, in the form of osmotic shock or fatiguing exercise, result in loose control of RyR function by the L-type channel. Thus, spontaneous $\mathrm{Ca}^{2+}$ sparks are observed. Uncontrolled calcium sparks function as a dystrophic signal for mammalian skeletal muscle.

Cardiac hypertrophy in spontaneous hypertensive rats is accompanied by the increase in the amplitude of $\mathrm{Ca}^{2+}$ sparks: big hearts, big sparks [120]. This alteration is not associated with changes of the density of ryanodine receptors, calsequestrin, junctin, triadin, SERCA, phospholamban, of the current density of L-type channels and of the level of SR $\mathrm{Ca}^{2+}$ content. The probable reason for big sparks in hypertrophic cardiomyocytes is related to elevated IP3 receptors expression, specifically in the junctional SR reticulum in close proximity to RyRs [121]. $\mathrm{Ca}^{2+}$ release via IP3 receptors sensitize RyRs, thereby enhancing $\mathrm{Ca}^{2+}$ release during E-C coupling. Diabetic cardiomyopathy is also characterized by changes of cardiac sparks amplitude. $\mathrm{Ca}^{2+}$ sparks in cardiomyocytes are smaller in amplitude and less frequent in obese type 2 diabetic mice in comparison to control mice, because of decreased SR $\mathrm{Ca}^{2+}$ load and lowered expression of RyR channels [122]. Reduced amplitude of $\mathrm{Ca}^{2+}$ transients and depression of SR $\mathrm{Ca}^{2+}$ load is also observed in streptomycin-induced diabetic rat hearts [123]. Another cardiac disorder that influences function of RyR2 receptors and thus formation of $\mathrm{Ca}^{2+}$ sparks is catecholaminergic polymorphic ventricular tachycardia (CPVT), a form of exercise-induced sudden cardiac death. Several RyR2 missense gain-of function mutations are found in CPVT carriers $[124,125]$. These mutations decrease the binding affinity of RyR2 for calstabin-2, a subunit that stabilizes the closed state of the RyR2 channel. The increased activity of mutant RyR2 leads to increased frequency of $\mathrm{Ca}^{2+}$ sparks in mice cardiomyocytes [126]. CPVT is caused also by mutations in calsequestrin, a $\mathrm{Ca}^{2+}$-storing protein of the SR, that indirectly inhibit RyR2 function at low luminal $\mathrm{Ca}^{2+}$ [127].

Changes in the efficiency of $\mathrm{Ca}^{2+}$ spark-BK channel (STOCs) coupling in arterial SMCs are associated with the arterial hypertension. Arterial hypertension is characterized by increased arterial vascular tone. $\mathrm{Ca}^{2+}$ sparks in arterial SMCs activate nearby BK channels providing a hyperpolarizing signal that opposes vasoconstriction [3]. A reduction of $\mathrm{Ca}^{2+}$ spark-BK channel coupling may cause hypertension. In angiotensin II-induced hypertension in rats, the expression of BK channel $\beta 1$ subunit in cerebral SMCs is downregulated. This leads to BK channel complexes with a decreased calcium sensitivity and a decreased ability to be activated by $\mathrm{Ca}^{2+}$ sparks [14]. BK channel $\beta 1$ subunit knockout mice have an increased arterial tone and blood pressure $[8,9]$. Diabetes mellitus has been reported to be associated with downregulation of BK $\beta 1$ subunits in retinal arteriolar smooth muscle of rats [128]. Correspondingly, upregulation of BK channel $\beta 1$ subunit in rat mesenteric SMCs induced by acute hemorrhagic shock results in hypersensitivity of $\mathrm{BK}$ channel to $\mathrm{Ca}^{2+}$ sparks that contributes to hypotension [129]. Removal of BK channels and loss of $\mathrm{Ca}^{2+}$ spark-BK channels coupling in corpus cavernosum smooth muscle lead to penile erectile dysfunction [130].

The properties of $\mathrm{Ca}^{2+}$ sparks and STOCs (amplitude, frequency, duration, and spatial distribution) are dependent on the correct function of many colocalized proteins, including those which determine $\mathrm{SR} \mathrm{Ca}^{2+}$ load and modulate the opening of RyR channels themselves. This makes RyR signaling prone for many disorders. The appearance of spontaneous $\mathrm{Ca}^{2+}$ sparks in skeletal muscle could serve as a marker of dystrophy. "Big" amplitudes of the cardiac $\mathrm{Ca}^{2+}$ sparks indicate hypertrophy. Loss of $\mathrm{Ca}^{2+}$ spark-BK channel (STOCs) coupling in arterial smooth muscle cells is associated with the arterial hypertension. Thus, analysis of properties of $\mathrm{Ca}^{2+}$ sparks and STOCs could be an important approach to characterize the functional state of muscle.

\section{Perspectives}

Despite of several studies performed to reveal the role of RyR isoforms in initiation and formation of calcium sparks in smooth muscle cells, the specific involvement of RyR1, RyR2, and RyR3 in local and global calcium signaling remains to be elucidated, in particular in arterial smooth muscle cells. Research progress is limited by the absence of selective pharmacological drugs and early embryonic and postnatal lethality of RyR1 and RyR2 knockout mice. Approaches to partially downregulate RyRs in arterial smooth muscle (e.g., by antisense oligonucleotides) seem to give results on local calcium signaling difficult to interpret, since the most efficacious calcium spark trigger appears to be the luminal SR $\mathrm{Ca}^{2+}$ which is slowly loaded via $\mathrm{Ca}^{2+}$ influx through $\mathrm{Ca}_{\mathrm{v}} 1.2$ channels and partial downregulation of RyR2 is associated with a compensatory uploading of the SR with $\mathrm{Ca}^{2+}$. In our view, a preferable approach to reveal the specific roles of RyR isoforms in arterial smooth muscle are experiments on inducible, smooth muscle-specific knockout mice lacking RyR subtypes. Generation of these mice is required for further research and will give future advances in the field.

\section{Acknowledgments}

This study is supported by the Deutsche Forschungsgemeinschaft. The authors thank Yoland Anistan for expert technical assistance. They also thank Kerstin Gorzelniak for performing the Taqman analysis of RyRs in rat cerebral arteries.

\section{References}

[1] H. Cheng and W. J. Lederer, "Calcium sparks," Physiological Reviews, vol. 88, no. 4, pp. 1491-1545, 2008.

[2] C. D. Benham and T. B. Bolton, "Spontaneous transient outward currents in single visceral and vascular smooth muscle cells of the rabbit," Journal of Physiology, vol. 381, pp. 385-406, 1986. 
[3] M. T. Nelson, H. Cheng, M. Rubart, et al., "Relaxation of arterial smooth muscle by calcium sparks," Science, vol. 270, no. 5236, pp. 633-637, 1995.

[4] G. J. Perez, A. D. Bonev, J. B. Patlak, and M. T. Nelson, "Functional coupling of ryanodine receptors to $\mathrm{K}(\mathrm{Ca})$ channels in smooth muscle cells from rat cerebral arteries," Journal of General Physiology, vol. 113, no. 2, pp. 229-237, 1999.

[5] J. Ledoux, M. E. Werner, J. E. Brayden, and M. T. Nelson, "Calcium-activated potassium channels and the regulation of vascular tone," Physiology, vol. 21, no. 1, pp. 69-79, 2006.

[6] Y. Tanaka, P. Meera, M. Song, H.-G. Knaus, and L. Toro, "Molecular constituents of maxi KCa channels in human coronary smooth muscle: predominant $\alpha+\beta$ subunit complexes," Journal of Physiology, vol. 502, no. 3, pp. 545-557, 1997.

[7] D. H. Cox, J. Cui, and R. W. Aldrich, "Separation of gating properties from permeation and block in mslo large conductance Ca-activated $\mathrm{K}^{+}$channels," Journal of General Physiology, vol. 109, no. 5, pp. 633-646, 1997.

[8] R. Brenner, G.J. Peréz, A. D. Bonev, et al., "Vasoregulation by the $\beta 1$ subunit of the calcium-activated potassium channel," Nature, vol. 407, no. 6806, pp. 870-876, 2000.

[9] S. Pluger, J. Faulhaber, M. Furstenau, et al., "Mice with disrupted BK channel $\beta 1$ subunit gene feature abnormal $\mathrm{Ca}^{2+}$ spark/STOC coupling and elevated blood pressure," Circulation research, vol. 87, no. 11, pp. E53-60, 2000.

[10] M. Sausbier, C. Arntz, I. Bucurenciu, et al., "Elevated blood pressure linked to primary hyperaldosteronism and impaired vasodilation in BK channel-deficient mice," Circulation, vol. 112, no. 1, pp. 60-68, 2005.

[11] Q. Wang, R. C. Hogg, and W. A. Large, "Properties of spontaneous inward currents recorded in smooth muscle cells isolated from the rabbit portal vein," Journal of Physiology, vol. 451, pp. 525-537, 1992.

[12] D. V. Gordienko, A. V. Zholos, and T. B. Bolton, "Membrane ion channels as physiological targets for local $\mathrm{Ca}^{2+}$ signalling," Journal of Microscopy, vol. 196, no. 3, pp. 305316, 1999.

[13] R. Bao, L. M. Lifshitz, R. A. Tuft, K. Bellve, K. E. Fogarty, and R. ZhuGe, "A close association of RyRs with highly dense clusters of $\mathrm{Ca}^{2+}$-activated $\mathrm{Cl}^{-}$channels underlies the activation of STICs by $\mathrm{Ca}^{2+}$ sparks in mouse airway smooth muscle," Journal of General Physiology, vol. 132, no. 1, pp. 145-160, 2008.

[14] G. C. Amberg, A. D. Bonev, C. F. Rossow, M. T. Nelson, and L. F. Santana, "Modulation of the molecular composition of large conductance, $\mathrm{Ca}^{2+}$ activated $\mathrm{K}^{+}$channels in vascular smooth muscle during hypertension," The Journal of Clinical Investigation, vol. 112, no. 5, pp. 717-724, 2003.

[15] E. Rios and G. Brum, "Involvement of dihydropyridine receptors in excitation-contraction coupling in skeletal muscle," Nature, vol. 325, no. 6106, pp. 717-720, 1987.

[16] M. G. Klein and M. F. Schneider, " $\mathrm{Ca}^{2+}$ sparks in skeletal muscle," Progress in Biophysics and Molecular Biology, vol. 92, no. 3, pp. 308-332, 2006.

[17] C. M. Armstrong, F. M. Bezanilla, and P. Horowicz, "Twitches in the presence of ethylene glycol bis ( -aminoethyl ether)N,N'-tetraacetic acid," Biochimica et Biophysica Acta, vol. 267, no. 3, pp. 605-608, 1972.

[18] A. Fabiato, "Calcium-induced release of calcium from the cardiac sarcoplasmic reticulum," American Journal of Physiology, vol. 245, no. 1, pp. C1-C14, 1983.

[19] M. L. Collier, G. Ji, Y.-X. Wang, and M. I. Kotlikoff, "Calcium-induced calcium release in smooth muscle: loose coupling between the action potential and calcium release," Journal of General Physiology, vol. 115, no. 5, pp. 653-662, 2000.

[20] M. I. Kotlikoff, "Calcium-induced calcium release in smooth muscle: the case for loose coupling," Progress in Biophysics and Molecular Biology, vol. 83, no. 3, pp. 171-191, 2003.

[21] K. Essin, A. Welling, F. Hofmann, F. C. Luft, M. Gollasch, and S. Moosmang, "Indirect coupling between $\mathrm{Ca}_{\mathrm{v}} 1.2$ channels and ryanodine receptors to generate $\mathrm{Ca}^{2+}$ sparks in murine arterial smooth muscle cells," The Journal of Physiology, vol. 584, no. 1, pp. 205-219, 2007.

[22] J. R. Lopez-Lopez, P. S. Shacklock, C. W. Balke, and W. G. Wier, "Local calcium transients triggered by single L-type calcium channel currents in cardiac cells," Science, vol. 268, no. 5213, pp. 1042-1045, 1995.

[23] L. F. Santana, H. Cheng, A. M. Gomez, M. B. Cannell, and W. J. Lederer, "Relation between the sarcolemmal Ca ${ }^{2+}$ Current and $\mathrm{Ca}^{2+}$ sparks and local control theories for cardiac excitation-contraction coupling," Circulation Research, vol. 78, no. 1, pp. 166-171, 1996.

[24] S. Moosmang, V. Schulla, A. Welling, et al., "Dominant role of smooth muscle L-type calcium channel Cav1.2 for blood pressure regulation," The EMBO Journal, vol. 22, no. 22, pp. 6027-6034, 2003.

[25] S. Gyorke, I. Gyorke, V. Lukyanenko, D. Terentyev, S. Viatchenko-Karpinski, and T. F. Wiesner, "Regulation of sarcoplasmic reticulum calcium release by luminal calcium in cardiac muscle," Frontiers in Bioscience, vol. 7, pp. d1454d1463, 2002.

[26] D. R. Laver, " $\mathrm{Ca}^{2+}$ stores regulate ryanodine receptor $\mathrm{Ca}^{2+}$ release channels via luminal and cytosolic $\mathrm{Ca}^{2+}$ sites," Clinical and Experimental Pharmacology and Physiology, vol. 34, no. 9, pp. 889-896, 2007.

[27] M. Fill and J. A. Copello, "Ryanodine receptor calcium release channels," Physiological Reviews, vol. 82, no. 4, pp. 893-922, 2002.

[28] M. W. Ledbetter, J. K. Preiner, C. F. Louis, and J. R. Mickelson, "Tissue distribution of ryanodine receptor isoforms and alleles determined by reverse transcription polymerase chain reaction," The Journal of Biological Chemistry, vol. 269, no. 50, pp. 31544-31551, 1994.

[29] V. Sorrentino, "The ryanodine receptor family of intracellular calcium release channels," Advances in Pharmacology, vol. 33, pp. 67-90, 1995.

[30] M. Santonastasi and X. H. T. Wehrens, "Ryanodine receptors as pharmacological targets for heart disease," Acta Pharmacologica Sinica, vol. 28, no. 7, pp. 937-944, 2007.

[31] C. M. Pabelick, Y. S. Prakash, M. S. Kannan, and G. C. Sieck, "Spatial and temporal aspects of calcium sparks in porcine tracheal smooth muscle cells," American Journal of Physiology, vol. 277, no. 5, pp. L1018-L1025, 1999.

[32] J. Nakai, T. Ogura, F. Protasi, C. Franzini-Armstrong, P. D. Allen, and K. G. Beam, "Functional nonequality of the cardiac and skeletal ryanodine receptors," Proceedings of the National Academy of Sciences of the United States of America, vol. 94, no. 3, pp. 1019-1022, 1997.

[33] C. F. Perez, A. Voss, I. N. Pessah, and P. D. Allen, "RyR1/RyR3 chimeras reveal that multiple domains of RyR1 are involved in skeletal-type E-C coupling," Biophysical Journal, vol. 84, no. 4, pp. 2655-2663, 2003.

[34] A. W. Trafford, G. C. Sibbring, M. E. Diaz, and D. A. Eisner, "The effects of low concentrations of caffeine on spontaneous Ca release in isolated rat ventricular myocytes," Cell Calcium, vol. 28, no. 4, pp. 269-276, 2000. 
[35] R. Zucchi and S. Ronca-Testoni, "The sarcoplasmic reticulum $\mathrm{Ca}^{2+}$ channel/ryanodine receptor: modulation by endogenous effectors, drugs and disease states," Pharmacological Reviews, vol. 49, no. 1, pp. 1-50, 1997.

[36] F. Zhao, P. Li, S. R. W. Chen, C. F. Louis, and B. R. Fruen, "Dantrolene inhibition of ryanodine receptor $\mathrm{Ca}^{2+}$ release channels. Molecular mechanism and isoform selectivity," The Journal of Biological Chemistry, vol. 276, no. 17, pp. 1381013816, 2001.

[37] Y. Zhang, G. G. Rodney, and M. F. Schneider, "Effects of azumolene on $\mathrm{Ca}^{2+}$ sparks in skeletal muscle fibers," Journal of Pharmacology and Experimental Therapeutics, vol. 314, no. 1, pp. 94-102, 2005.

[38] R. A. Bannister, I. N. Pessah, and K. G. Beam, "The skeletal L-type $\mathrm{Ca}^{2+}$ current is a major contributor to excitationcoupled $\mathrm{Ca}^{2+}$ entry," Journal of General Physiology, vol. 133, no. 1, pp. 79-91, 2009.

[39] H. H. Valdivia, M. S. Kirby, W. J. Lederer, and R. Coronado, "Scorpion toxins targeted against the sarcoplasmic reticulum $\mathrm{Ca}^{2+}$-release channel of skeletal and cardiac muscle," Proceedings of the National Academy of Sciences of the United States of America, vol. 89, no. 24, pp. 12185-12189, 1992.

[40] A. Tripathy, W. Resch, L. E. Xu, H. H. Valdivia, and G. Meissner, "Imperatoxin A induces subconductance states in $\mathrm{Ca}^{2+}$ release channels (ryanodine receptors) of cardiac and skeletal muscle," Journal of General Physiology, vol. 111, no. 5, pp. 679-690, 1998.

[41] A. Shtifman, C. W. Ward, J. Wang, H. H. Valdivia, and M. F. Schneider, "Effects of imperatoxin A on local sarcoplasmic reticulum $\mathrm{Ca}^{2+}$ release in frog skeletal muscle," Biophysical Journal, vol. 79, no. 2, pp. 814-827, 2000.

[42] D. Terentyev, S. Viatchenko-Karpinski, H. H. Valdivia, A. L. Escobar, and S. Györke, "Luminal $\mathrm{Ca}^{2+}$ controls termination and refractory behavior of $\mathrm{Ca}^{2+}$-induced $\mathrm{Ca}^{2+}$ release in cardiac myocytes," Circulation Research, vol. 91, no. 5, pp. 414-420, 2002.

[43] H. Takeshima, M. Iino, H. Takekura, et al., "Excitationcontraction uncoupling and muscular degeneration in mice lacking functional skeletal muscle ryanodine-receptor gene," Nature, vol. 369, no. 6481, pp. 556-559, 1994.

[44] H. Takeshima, S. Komazaki, K. Hirose, M. Nishi, T. Noda, and M. Ino, "Embryonic lethality and abnormal cardiac myocytes in mice lacking ryanodine receptor type 2," The EMBO Journal, vol. 17, no. 12, pp. 3309-3316, 1998.

[45] H. Takeshima, T. Ikemoto, M. Nishi, et al., "Generation and characterization of mutant mice lacking ryanodine receptor type 3," The Journal of Biological Chemistry, vol. 271, no. 33, pp. 19649-19652, 1996.

[46] P. Tarroni, D. Rossi, A. Conti, and V. Sorrentino, "Expression of the ryanodine receptor type 3 calcium release channel during development and differentiation of mammalian skeletal muscle cells," The Journal of Biological Chemistry, vol. 272, no. 32, pp. 19808-19813, 1997.

[47] A. Conti, C. Reggiani, and V. Sorrentino, "Selective expression of the type 3 isoform of ryanodine receptor $\mathrm{Ca}^{2+}$ release channel (RyR3) in a subset of slow fibers in diaphragm and cephalic muscles of adult rabbits," Biochemical and Biophysical Research Communications, vol. 337, no. 1, pp. 195-200, 2005.

[48] M. W. Conklin, C. A. Ahern, P. Vallejo, V. Sorrentino, H. Takeshima, and R. Coronado, "Comparison of $\mathrm{Ca}^{2+}$ sparks produced independently by two ryanodine receptor isoforms (type 1 or type 3)," Biophysical Journal, vol. 78, no. 4, pp. $1777-1785,2000$.
[49] A. Conti, L. Gorza, and V. Sorrentino, "Differential distribution of ryanodine receptor type 3 (RyR3) gene product in mammalian skeletal muscles," Biochemical Journal, vol. 316, no. 1, pp. 19-23, 1996.

[50] F. Bertocchini, C. E. Ovitt, A. Conti, et al., "Requirement for the ryanodine receptor type 3 for efficient contraction in neonatal skeletal muscles," The EMBO Journal, vol. 16, no. 23, pp. 6956-6963, 1997.

[51] N. Shirokova, J. García, and E. Ríos, "Local calcium release in mammalian skeletal muscle," Journal of Physiology, vol. 512, no. 2, pp. 377-384, 1998.

[52] C. W. Ward and W. J. Lederer, "Ghost sparks," Nature Cell Biology, vol. 7, no. 5, pp. 457-459, 2005.

[53] X. Wang, N. Weisleder, C. Collet, et al., "Uncontrolled calcium sparks act as a dystrophic signal for mammalian skeletal muscle," Nature Cell Biology, vol. 7, no. 5, pp. 525530, 2005.

[54] N. Weisleder, C. Ferrante, Y. Hirata, et al., "Systemic ablation of RyR3 alters $\mathrm{Ca}^{2+}$ spark signaling in adult skeletal muscle," Cell Calcium, vol. 42, no. 6, pp. 548-555, 2007.

[55] C. W. Ward, M. F. Schneider, D. Castillo, et al., "Expression of ryanodine receptor RyR3 produces $\mathrm{Ca}^{2+}$ sparks in dyspedic myotubes," Journal of Physiology, vol. 525, no. 1, pp. 91-103, 2000.

[56] J. L. Sutko and J. A. Airey, "Ryanodine receptor $\mathrm{Ca}^{2+}$ release channels: does diversity in form equal diversity in function?" Physiological Reviews, vol. 76, no. 4, pp. 1027-1071, 1996.

[57] A. Tsugorka, E. Rios, and L. A. Blatter, "Imaging elementary events of calcium release in skeletal muscle cells," Science, vol. 269, no. 5231, pp. 1723-1726, 1995.

[58] M. G. Klein, H. Cheng, L. F. Santana, Y.-H. Jiang, W. J. Lederer, and M. F. Schneider, "Two mechanisms of quantized calcium release in skeletal muscle," Nature, vol. 379, no. 6564, pp. 455-458, 1996.

[59] S. Pouvreau, L. Royer, J. Yi, et al., " $\mathrm{Ca}^{2+}$ sparks operated by membrane depolarization require isoform 3 ryanodine receptor channels in skeletal muscle," Proceedings of the National Academy of Sciences of the United States of America, vol. 104, no. 12, pp. 5235-5240, 2007.

[60] C. Legrand, E. Giacomello, C. Berthier, B. Allard, V. Sorrentino, and V. Jacquemond, "Spontaneous and voltageactivated $\mathrm{Ca}^{2+}$ release in adult mouse skeletal muscle fibres expressing the type 3 ryanodine receptor," The Journal of Physiology, vol. 586, no. 2, pp. 441-457, 2008.

[61] H.-T. Yang, D. Tweedie, S. Wang, et al., "The ryanodine receptor modulates the spontaneous beating rate of cardiomyocytes during development," Proceedings of the National Academy of Sciences of the United States of America, vol. 99, no. 14, pp. 9225-9230, 2002.

[62] S. Gyorke and D. Terentyev, "Modulation of ryanodine receptor by luminal calcium and accessory proteins in health and cardiac disease," Cardiovascular Research, vol. 77, no. 2, pp. 245-255, 2008.

[63] E. Rios and S. Gyorke, "Calsequestrin, triadin and more: the molecules that modulate calcium release in cardiac and skeletal muscle," Journal of Physiology, vol. 587, no. 13, pp. 3069-3070, 2009.

[64] F. Coussin, N. Macrez, J.-L. Morel, and J. Mironneau, "Requirement of ryanodine receptor subtypes 1 and 2 for $\mathrm{Ca}^{2+}$-induced $\mathrm{Ca}^{2+}$ release in vascular myocytes," The Journal of Biological Chemistry, vol. 275, no. 13, pp. 9596-9603, 2000.

[65] M. Lohn, W. Jessner, M. Furstenau, et al., "Regulation of calcium sparks and spontaneous transient outward currents 
by RyR3 in arterial vascular smooth muscle cells," Circulation Research, vol. 89, no. 11, pp. 1051-1057, 2001.

[66] J. Mironneau, F. Coussin, L. H. Jeyakumar, S. Fleischer, C. Mironneau, and N. Macrez, "Contribution of ryanodine receptor subtype 3 to $\mathrm{Ca}^{2+}$ responses in $\mathrm{Ca}^{2+}$-overloaded cultured rat portal vein myocytes," The Journal of Biological Chemistry, vol. 276, no. 14, pp. 11257-11264, 2001.

[67] G. Ji, M. E. Feldman, K. S. Greene, V. Sorrentino, H.-B. Xin, and M. I. Kotlikoff, "RYR2 proteins contribute to the formation of $\mathrm{Ca}^{2+}$ sparks in smooth muscle," Journal of General Physiology, vol. 123, no. 4, pp. 377-386, 2004.

[68] N. Fritz, J.-L. Morel, L. H. Jeyakumar, et al., "RyR1specific requirement for depolarization-induced $\mathrm{Ca}^{2+}$ sparks in urinary bladder smooth muscle," Journal of Cell Science, vol. 120, no. 21, pp. 3784-3791, 2007.

[69] S. Hotta, K. Morimura, S. Ohya, K. Muraki, H. Takeshima, and Y. Imaizumi, "Ryanodine receptor type 2 deficiency changes excitation-contraction coupling and membrane potential in urinary bladder smooth muscle," Journal of Physiology, vol. 582, no. 2, pp. 489-506, 2007.

[70] X.-Q. Li, Y.-M. Zheng, R. Rathore, J. Ma, H. Takeshima, and Y.-X. Wang, "Genetic evidence for functional role of ryanodine receptor 1 in pulmonary artery smooth muscle cells," Pflugers Archiv European Journal of Physiology, vol. 457, no. 4, pp. 771-783, 2009.

[71] Y.-X. Wang, Y.-M. Zheng, Q.-B. Mei, et al., "FKBP12.6 and cADPR regulation of $\mathrm{Ca}^{2+}$ release in smooth muscle cells," American Journal of Physiology, vol. 286, pp. C538-C546, 2004.

[72] K. Morimura, Y. Ohi, H. Yamamura, S. Ohya, K. Muraki, and Y. Imaizumi, "Two-step $\mathrm{Ca}^{2+}$ intracellular release underlies excitation-contraction coupling in mouse urinary bladder myocytes," American Journal of Physiology, vol. 290, no. 2, pp. C388-C403, 2006.

[73] A. Sonnleitner, A. Conti, F. Bertocchini, H. Schindler, and V. Sorrentino, "Functional properties of the ryanodine receptor type 3 (RyR3) $\mathrm{Ca}^{2+}$ release channel," The EMBO Journal, vol. 17, no. 10, pp. 2790-2798, 1998.

[74] T. Murayama, T. Oba, E. Katayama, et al., "Further characterization of the type 3 ryanodine receptor (RyR3) purified from rabbit diaphragm," The Journal of Biological Chemistry, vol. 274, no. 24, pp. 17297-17308, 1999.

[75] M. Gollasch, G. C. Wellman, H. J. Knot, et al., "Ontogeny of local sarcoplasmic reticulum $\mathrm{Ca}^{2+}$ signals in cerebral arteries: $\mathrm{Ca}^{2+}$ sparks as elementary physiological events," Circulation Research, vol. 83, no. 11, pp. 1104-1114, 1998.

[76] S. A. Reading and J. E. Brayden, "Central role of TRPM4 channels in cerebral blood flow regulation," Stroke, vol. 38, no. 8, pp. 2322-2328, 2007.

[77] M. Blüher, S. Engeli, N. Klöting, et al., "Dysregulation of the peripheral and adipose tissue endocannabinoid system in human abdominal obesity," Diabetes, vol. 55, no. 11, pp. 3053-3060, 2006.

[78] H. Kong, R. Wang, W. Chen, et al., "Skeletal and cardiac ryanodine receptors exhibit different responses to $\mathrm{Ca}^{2+}$ overload and luminal $\mathrm{Ca}^{2+}$," Biophysical Journal, vol. 92, no. 8, pp. 2757-2770, 2007.

[79] D. R. Laver, "Luminal $\mathrm{Ca}^{2+}$ activation of cardiac ryanodine receptors by luminal and cytoplasmic domains," European Biophysics Journal, vol. 39, no. 1, pp. 19-26, 2009.

[80] L. Xu and G. Meissner, "Regulation of cardiac muscle $\mathrm{Ca}^{2+}$ release channel by sarcoplasmic reticulum lumenal $\mathrm{Ca}^{2+}$," Biophysical Journal, vol. 75, no. 5, pp. 2302-2312, 1998.
[81] I. Gyorke and S. Gyorke, "Regulation of the cardiac ryanodine receptor channel by luminal $\mathrm{Ca}^{2+}$ involves luminal $\mathrm{Ca}^{2+}$ sensing sites," Biophysical Journal, vol. 75, no. 6, pp. 2801-2810, 1998.

[82] S. Gyorke, V. Lukyanenko, I. Gyorke, et al., "Dual effects of tetracaine on spontaneous calcium release in rat ventricular myocytes," Journal of Physiology, vol. 500, no. 2, pp. 297-309, 1997.

[83] S. Y. Cheranov and J. H. Jaggar, "Sarcoplasmic reticulum calcium load regulates rat arterial smooth muscle calcium sparks and transient $\mathrm{K}_{\mathrm{ca}}$ currents," Journal of Physiology, vol. 544, no. 1, pp. 71-84, 2002.

[84] T. M. Curtis, J. Tumelty, M. T. Stewart, et al., "Modification of smooth muscle $\mathrm{Ca}^{2+}$-sparks by tetracaine: evidence for sequential RyR activation," Cell Calcium, vol. 43, no. 2, pp. 142-154, 2008.

[85] R. ZhuGe, R. A. Tuft, K. E. Fogarty, K. Bellve, F. S. Fay, and J. V. Walsh Jr., "The influence of sarcoplasmic reticulum $\mathrm{Ca}^{2+}$ concentration on $\mathrm{Ca}^{2+}$ sparks and spontaneous transient outward currents in single smooth muscle cells," Journal of General Physiology, vol. 113, no. 2, pp. 215-228, 1999.

[86] G. C. Wellman, L. F. Santana, A. D. Bonev, and M. T. Nelson, "Role of phospholamban in the modulation of arterial $\mathrm{Ca}^{2+}$ sparks and $\mathrm{Ca}^{2+}$-activated $\mathrm{K}^{+}$channels by cAMP," American Journal of Physiology, vol. 70281, pp. C1029-C1037, 2001.

[87] E. F. Farrell, A. Antaramian, A. Rueda, A. M. Gomez, and H. H. Valdivia, "Sorcin inhibits calcium release and modulates excitation-contraction coupling in the heart," The Journal of Biological Chemistry, vol. 278, no. 36, pp. 34660-34666, 2003.

[88] A. Rueda, M. Song, L. Toro, E. Stefani, and H. H. Valdivia, "Sorcin modulation of $\mathrm{Ca}^{2+}$ sparks in rat vascular smooth muscle cells," Journal of Physiology, vol. 576, no. 3, pp. 887901, 2006.

[89] M. R. Fowler, G. Colotti, E. Chiancone, Y. Higuchi, T. Seidler, and G. L. Smith, "Complex modulation of L-type $\mathrm{Ca}^{2+}$ current inactivation by sorcin in isolated rabbit cardiomyocytes," Pflugers Archiv European Journal of Physiology, vol. 457, no. 5, pp. 1049-1060, 2009.

[90] T. Matsumoto, Y. Hisamatsu, T. Ohkusa, et al., "Sorcin interacts with sarcoplasmic reticulum $\mathrm{Ca}^{2+}$-ATPase and modulates excitation-contraction coupling in the heart," Basic Research in Cardiology, vol. 100, no. 3, pp. 250-262, 2005.

[91] L. P. Collis, M. B. Meyers, J. Zhang, et al., "Expression of a sorcin missense mutation in the heart modulates excitationcontraction coupling," FASEB Journal, vol. 21, no. 2, pp. 475487, 2007.

[92] H. H. Valdivia, "Modulation of intracellular $\mathrm{Ca}^{2+}$ levels in the heart by sorcin and FKBP12, two accessory proteins of ryanodine receptors," Trends in Pharmacological Sciences, vol. 19, no. 12, pp. 479-483, 1998.

[93] S. Mohiddin, A. Antaramian, E. F. Farrell, et al., "A naturally-occurring sorcin missense mutation (F112L) is associated with hypertrophic cardiomyopathy, hypertension, and impaired modulation of cardiac ryanodine receptor," Circulation, vol. 106, p. 319, 2002.

[94] S. Franceschini, A. Ilari, D. Verzili, et al., "Molecular basis for the impaired function of the natural F112L sorcin mutant: $\mathrm{X}$-ray crystal structure, calcium affinity, and interaction with annexin VII and the ryanodine receptor," FASEB Journal, vol. 22, no. 1, pp. 295-306, 2008.

[95] P. F. Worley, W. Zeng, G. Huang, et al., "Homer proteins in $\mathrm{Ca}^{2+}$ signaling by excitable and non-excitable cells," Cell Calcium, vol. 42, no. 4-5, pp. 363-371, 2007. 
[96] M. M. Soloviev, F. Ciruela, W.-Y. Chan, and R. A. J. McIlhinney, "Mouse brain and muscle tissues constitutively express high levels of homer proteins," European Journal of Biochemistry, vol. 267, no. 3, pp. 634-639, 2000.

[97] W. Feng, J. Tu, P. Pouliquin, et al., "Dynamic regulation of ryanodine receptor type 1 (RyR 1 ) channel activity by Homer 1," Cell Calcium, vol. 43, no. 3, pp. 307-314, 2008.

[98] P. Pouliquin, S. M. Pace, and A. F. Dulhunty, "In vitro modulation of the cardiac ryanodine receptor activity by Homer 1," Pflugers Archiv European Journal of Physiology, vol. 458, no. 4, pp. 723-732, 2009.

[99] C. W. Ward, W. Feng, J. Tu, I. N. Pessah, P. K. Worley, and M. F. Schneider, "Homer protein increases activation of $\mathrm{Ca}^{2+}$ sparks in permeabilized skeletal muscle," The Journal of Biological Chemistry, vol. 279, no. 7, pp. 5781-5787, 2004.

[100] G. Huang, J. Y. Kim, M. Dehoff, et al., " $\mathrm{Ca}^{2+}$ signaling in microdomains: homerl mediates the interaction between RyR2 and $\mathrm{Ca}_{\mathrm{v}} 1.2$ to regulate excitation-contraction coupling," The Journal of Biological Chemistry, vol. 282, no. 19, pp. 14283-14290, 2007.

[101] R. Zalk, S. E. Lehnart, and A. R. Marks, "Modulation of the ryanodine receptor and intracellular calcium," Annual Review of Biochemistry, vol. 76, pp. 367-385, 2007.

[102] J. Liu, J. D. Farmer Jr., W. S. Lane, J. Friedman, I. Weissman, and S. L. Schreiber, "Calcineurin is a common target of cyclophilin-cyclosporin A and FKBP-FK506 complexes," Cell, vol. 66, no. 4, pp. 807-815, 1991.

[103] J. Heitman, N. R. Movva, and M. N. Hall, "Targets for cell cycle arrest by the immunosuppressant rapamycin in yeast," Science, vol. 253, no. 5022, pp. 905-909, 1991.

[104] E. Lam, M. M. Martin, A. P. Timerman, et al., "A novel FK506 binding protein can mediate the immunosuppressive effects of FK506 and is associated with the cardiac ryanodine receptor," The Journal of Biological Chemistry, vol. 270, no. 44, pp. 26511-26522, 1995.

[105] W. Tang, C. P. Ingalls, W. J. Durham, et al., "Altered excitation-contraction coupling with skeletal muscle specific FKBP12 deficiency," FASEB Journal, vol. 18, no. 13, pp. 15971599, 2004.

[106] S. Reiken, A. Lacampagne, H. Zhou, et al., "PKA phosphorylation activates the calcium release channel (ryanodine receptor)-in skeletal muscle: defective regulation in heart failure," Journal of Cell Biology, vol. 160, no. 6, pp. 919-928, 2003.

[107] J. Almassy, M. Sztretye, B. Lukacs, et al., "Effects of K-201 on the calcium pump and calcium release channel of rat skeletal muscle," Pflugers Archiv European Journal of Physiology, vol. 457, no. 1, pp. 171-183, 2008.

[108] H.-B. Xin, T. Senbonmatsu, D.-S. Cheng, et al., "Oestrogen protects FKBP12.6 null mice from cardiac hypertrophy," Nature, vol. 416, no. 6878, pp. 334-337, 2002.

[109] R.-P. Xiao, H. H. Valdivia, K. Bogdanov, C. Valdivia, E. G. Lakatta, and H. Cheng, "The immunophilin FK506-binding protein modulates $\mathrm{Ca}^{2+}$ release channel closure in rat heart," Journal of Physiology, vol. 500, no. 2, pp. 343-354, 1997.

[110] Z. Su, K. Sugishita, F. Li, M. Ritter, and W. H. Barry, "Effects of FK506 on $\left[\mathrm{Ca}^{2+}\right]$ i differ in mouse and rabbit ventricular myocytes," Journal of Pharmacology and Experimental Therapeutics, vol. 304, no. 1, pp. 334-341, 2003.

[111] E. McCall, L. Li, H. Satoh, T. R. Shannon, L. A. Blatter, and D. M. Bers, "Effects of FK-506 on contraction and $\mathrm{Ca}^{2+}$ transients in rat cardiac myocytes," Circulation Research, vol. 79, no. 6, pp. 1110-1121, 1996.
[112] A. M. Gomez, I. Schuster, J. Fauconnier, J. Prestle, G. Hasenfuss, and S. Richard, "FKBP12.6 overexpression decreases $\mathrm{Ca}^{2+}$ spark amplitude but enhances $\left[\mathrm{Ca}^{2+}\right] \mathrm{i}$ transient in rat cardiac myocytes," American Journal of Physiology, vol. 287, no. 5, pp. H1987-H1993, 2004.

[113] C. M. Loughrey, T. Seidler, S. L. W. Miller, et al., "Over-expression of FK506-binding protein FKB12.6 alters excitation-contraction coupling in adult rabbit cardiomyocytes," Journal of Physiology, vol. 556, no. 3, pp. 919-934, 2004.

[114] B. Gellen, M. Fernandez-Velasco, F. Briec, et al., "Conditional FKBP12.6 overexpression in mouse cardiac myocytes prevents triggered ventricular tachycardia through specific alterations in excitation-contraction coupling," Circulation, vol. 117, no. 14, pp. 1778-1786, 2008.

[115] J. Xiao, X. Tian, P. P. Jones, et al., "Removal of FKBP12.6 does not alter the conductance and activation of the cardiac ryanodine receptor or the susceptibility to stress-induced ventricular arrhythmias," The Journal of Biological Chemistry, vol. 282, no. 48, pp. 34828-34838, 2007.

[116] Th. Weidelt and G. Isenberg, "Augmentation of SR $\mathrm{Ca}^{2+}$ release by rapamycin and FK506 causes $\mathrm{K}^{+}$-channel activation and membrane hyperpolarization in bladder smooth muscle," British Journal of Pharmacology, vol. 129, no. 7, pp. 1293-1300, 2000.

[117] W.-X. Tang, Y.-F. Chen, A.-P. Zou, W. B. Campbell, and P.-L. Li, "Role of FKBP12.6 in cADPR-induced activation of reconstituted ryanodine receptors from arterial smooth muscle," American Journal of Physiology, vol. 282, no. 4, pp. H1304-H1310, 2002.

[118] C. Long, L. G. Cook, G.-Y. Wu, and B. M. Mitchell, "Removal of Fkbp12/12.6 from endothelial ryanodine receptors leads to an intracellular calcium leak and endothelial dysfunction," Arteriosclerosis, Thrombosis, and Vascular Biology, vol. 27, no. 7, pp. 1580-1586, 2007.

[119] N. Weisleder, M. Brotto, S. Komazaki, et al., "Muscle aging is associated with compromised $\mathrm{Ca}^{2+}$ spark signaling and segregated intracellular $\mathrm{Ca}^{2+}$ release," Journal of Cell Biology, vol. 174, no. 5, pp. 639-645, 2006.

[120] S. R. Shorofsky, R. Aggarwal, M. Corretti, et al., "Cellular mechanisms of altered contractility in the hypertrophied heart: big hearts, big sparks," Circulation Research, vol. 84, no. 4, pp. 424-434, 1999.

[121] D. Harzheim, M. Movassagh, R. S.-Y. Foo, et al., "Increased InsP3Rs in the junctional sarcoplasmic reticulum augment $\mathrm{Ca}^{2+}$ transients and arrhythmias associated with cardiac hypertrophy," Proceedings of the National Academy of Sciences of the United States of America, vol. 106, no. 27, pp. 1140611411, 2009.

[122] L. Pereira, J. Matthes, I. Schuster, et al., "Mechanisms of $\left[\mathrm{Ca}^{2+}\right]_{\mathrm{i}}$ transient decrease in cardiomyopathy of $\mathrm{db} / \mathrm{db}$ type 2 diabetic mice," Diabetes, vol. 55, no. 3, pp. 608-615, 2006.

[123] N. Yaras, M. Ugur, S. Ozdemir, et al., "Effects of diabetes on ryanodine receptor Ca release channel (RyR2) and $\mathrm{Ca}^{2+}$ homeostasis in rat heart," Diabetes, vol. 54, no. 11, pp. 30823088, 2005.

[124] X. H. T. Wehrens, S. E. Lehnart, F. Huang, et al., "FKBP12.6 deficiency and defective calcium release channel (ryanodine receptor) function linked to exercise-induced sudden cardiac death," Cell, vol. 113, no. 7, pp. 829-840, 2003.

[125] S. E. Lehnart, X. H. Wehrens, P. J. Laitinen, et al., "Sudden death in familial polymorphic ventricular tachycardia associated with calcium release channel (ryanodine receptor) leak," Circulation, vol. 109, no. 25, pp. 3208-3214, 2004. 
[126] S. E. Lehnart, M. Mongillo, A. Bellinger, et al., "Leaky $\mathrm{Ca}^{2+}$ release channel/ryanodine receptor 2 causes seizures and sudden cardiac death in mice," The Journal of Clinical Investigation, vol. 118, no. 6, pp. 2230-2245, 2008.

[127] S. Gyorke, "Molecular basis of catecholaminergic polymorphic ventricular tachycardia," Heart Rhythm, vol. 6, no. 1, pp. 123-129, 2009.

[128] M. K. McGahon, D. P. Dash, A. Arora, et al., "Diabetes downregulates large-conductance $\mathrm{Ca}^{2+}$-activated potassium $\beta 1$ channel subunit in retinal arteriolar smooth muscle," Circulation Research, vol. 100, no. 5, pp. 703-711, 2007.

[129] G. Zhao, Y. Zhao, B. Pan, et al., "Hypersensitivity of BKCa to $\mathrm{Ca}^{2+}$ sparks underlies hyporeactivity of arterial smooth muscle in shock," Circulation Research, vol. 101, no. 5, pp. 493-502, 2007.

[130] M. E. Werner, P. Zvara, A. L. Meredith, R. W. Aldrich, and M. T. Nelson, "Erectile dysfunction in mice lacking the largeconductance calcium-activated potassium (BK) channel," Journal of Physiology, vol. 567, no. 2, pp. 545-556, 2005. 

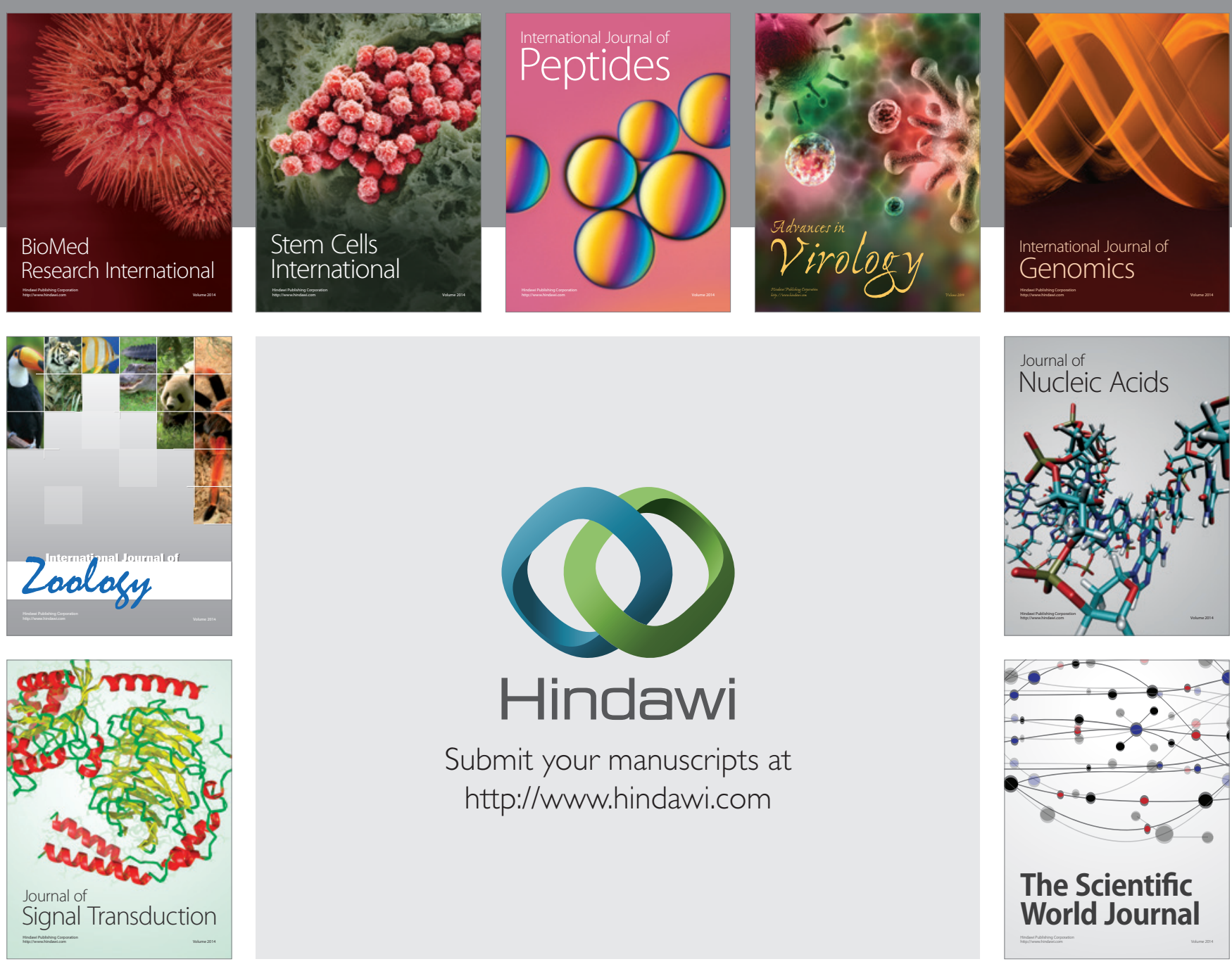

Submit your manuscripts at

http://www.hindawi.com
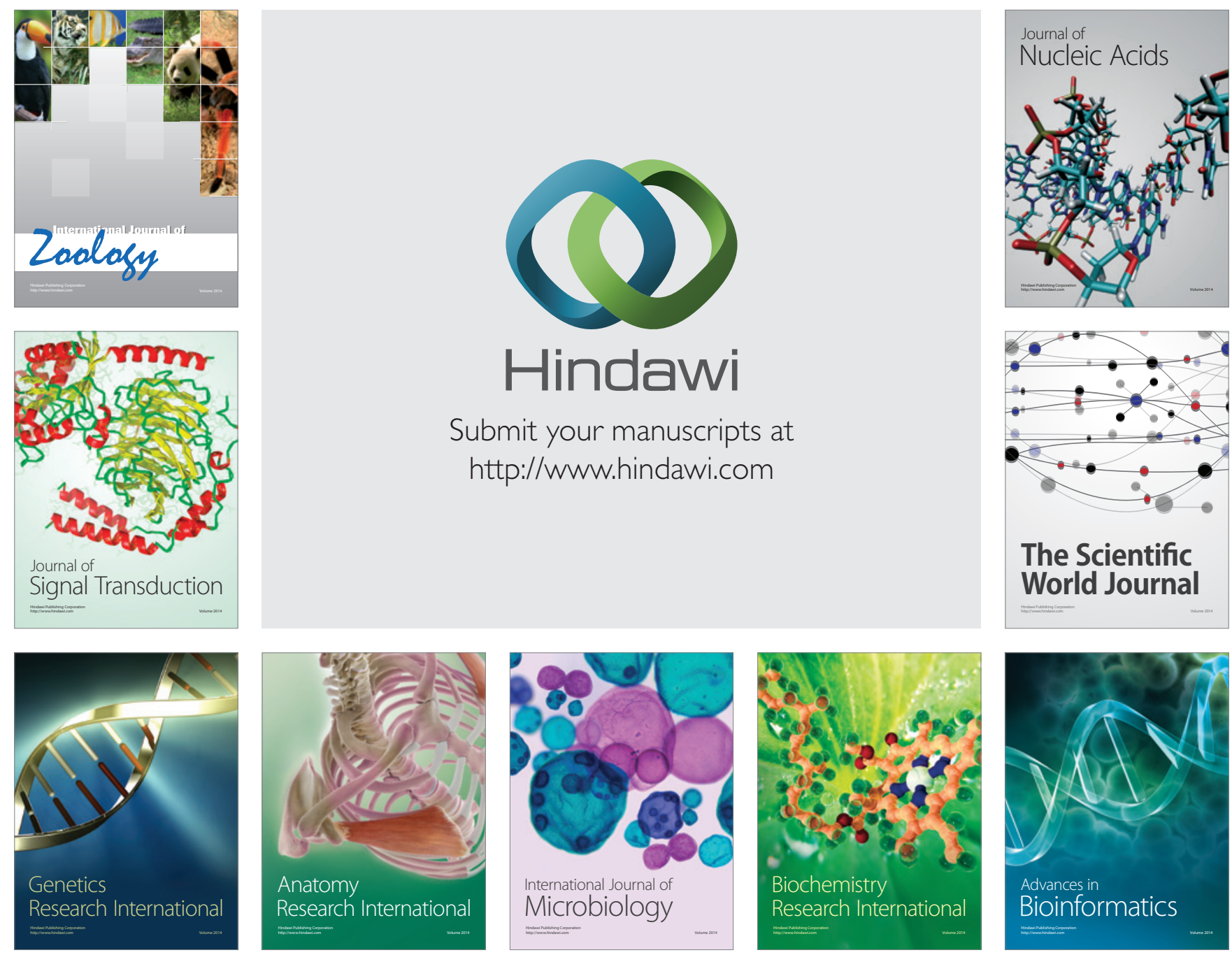

The Scientific World Journal
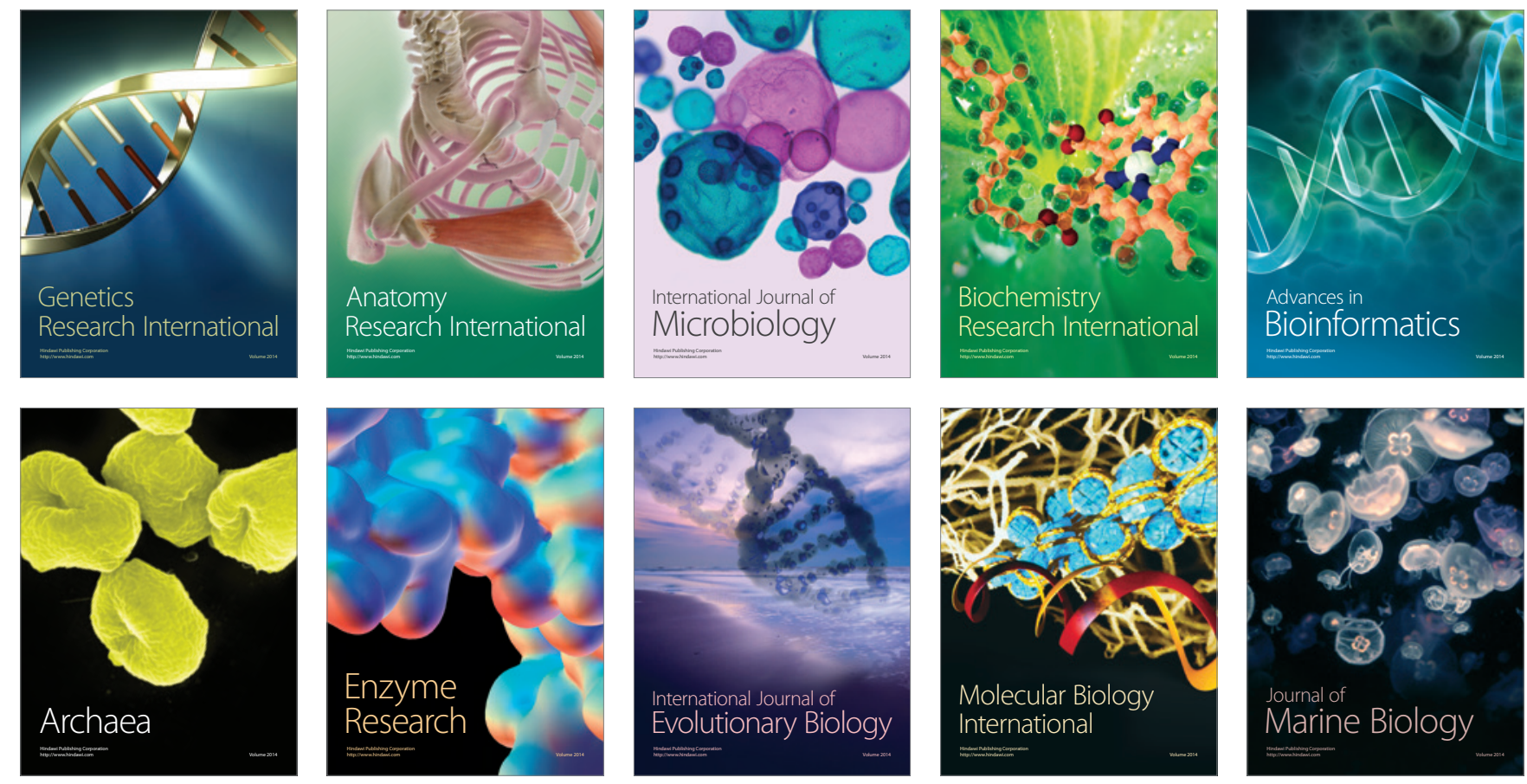